\title{
Systematic review of the relationships between sedentary behaviour and health indicators in the early years ( $0-4$ years)
}

Veronica J. Poitras ${ }^{1 *}$, Casey E. Gray ${ }^{1}$, Xanne Janssen², Salome Aubert ${ }^{1}$, Valerie Carson ${ }^{3}$, Guy Faulkner ${ }^{4}$, Gary S. Goldfield ${ }^{1}$, John J. Reilly' ${ }^{2}$ Margaret Sampson ${ }^{1,5}$ and Mark S. Tremblay ${ }^{1}$

\begin{abstract}
Background: The purpose of this systematic review was to examine the relationships between sedentary behaviour (SB) and health indicators in children aged 0 to 4 years, and to determine what doses of SB (i.e., duration, patterns [frequency, interruptions], and type) were associated with health indicators.

Methods: Online databases were searched for peer-reviewed studies that met the a priori inclusion criteria: population (apparently healthy, 1 month to 4.99 years), intervention/exposure and comparator (durations, patterns, and types of SB), and outcome/health indicator (critical: adiposity, motor development, psychosocial health, cognitive development; important: bone and skeletal health, cardiometabolic health, fitness, risks/harm). The quality of the evidence was assessed by study design and outcome using the Grading of Recommendations Assessment, Development and Evaluation (GRADE) framework.
\end{abstract}

Results: Due to heterogeneity, meta-analyses were not possible; instead, narrative syntheses were conducted, structured around the health indicator and type of SB. A total of 96 studies were included (195,430 participants from 33 countries). Study designs were: randomized controlled trial $(n=1)$, case-control $(n=3)$, longitudinal $(n=25)$, longitudinal with additional cross-sectional analyses $(n=5)$, and cross-sectional $(n=62)$. Evidence quality ranged from "very low" to "moderate". Associations between objectively measured total sedentary time and indicators of adiposity and motor development were predominantly null. Associations between screen time and indicators of adiposity, motor or cognitive development, and psychosocial health were primarily unfavourable or null. Associations between reading/storytelling and indicators of cognitive development were favourable or null. Associations between time spent seated (e.g., in car seats or strollers) or in the supine position, and indicators of adiposity and motor development, were primarily unfavourable or null. Data were scarce for other outcomes.

Conclusions: These findings continue to support the importance of minimizing screen time for disease prevention and health promotion in the early years, but also highlight the potential cognitive benefits of interactive nonscreen-based sedentary behaviours such as reading and storytelling. Additional high-quality research using valid and reliable measures is needed to more definitively establish the relationships between durations, patterns, and types of SB and health indicators, and to provide insight into the appropriate dose of SB for optimal health in the early years.

Keywords: Sedentary behaviour, Infants, Toddlers, Preschoolers, Early years, Screen time, Sitting, Reading, Adiposity, Motor development, Cognitive development, Bone and skeletal health, Cardiometabolic health, Fitness, Risks

\footnotetext{
* Correspondence: veronicapoitras@gmail.com

${ }^{1}$ Healthy Active Living and Obesity Research Group, RI \#1, Children's Hospital

of Eastern Ontario Research Institute, 401 Smyth Road, Ottawa, ON K1H 8L1,

Canada

Full list of author information is available at the end of the article
} International License (http://creativecommons.org/licenses/by/4.0/), which permits unrestricted use, distribution, and reproduction in any medium, provided you give appropriate credit to the original author(s) and the source, provide a link to the Creative Commons license, and indicate if changes were made. The Creative Commons Public Domain Dedication waiver (http://creativecommons.org/publicdomain/zero/1.0/) applies to the data made available in this article, unless otherwise stated. 


\section{Background}

Sedentary behaviour is defined as any waking behaviour with an energy expenditure of $\leq 1.5$ metabolic equivalents (METs) while in a sitting or reclining posture [1]. It is increasingly recognized that too much sedentary behaviour can have negative health effects across the lifespan [2-4], which are distinct from those that result from low physical activity [5]. This may be of particular importance in the early years of life, given that these years are critical for growth and development, and that lifestyle behaviours established early in life tend to track over time [6-8].

In this regard, the Canadian Sedentary Behaviour Guidelines for the Early Years (ages 0-4 years) [9], and guidelines in other countries around the world (e.g., Australia [10] and USA [11]), recommend that children $<2$ years of age have no exposure to screens, and that those aged 2 to 4 years have $<1 \mathrm{~h}$ /day of screen time. In addition, guidelines (e.g., in Canada [9], Australia [10], and the United Kingdom [12]) recommend that parents and caregivers minimize the time that children spend sitting or being restrained (e.g., in a stroller or high chair) while awake.

In contrast to these recommendations, $\geq 80 \%$ of young children are exposed to screens before the age of 2 years $[13,14]$, only $22 \%$ of Canadian children aged 3 to 4 years are meeting the screen time guidelines of $<1 \mathrm{~h} /$ day, and on average parent-reported screen time for this age group is $2.0 \mathrm{~h}$ /day [15]. Moreover, young children are spending a substantial proportion of their time sedentary, and no guidance regarding an "appropriate" amount of total sedentary time exists. This is a notable gap, given that a recent review including data from 10 countries reported that children aged 2 to 5 years were sedentary for $34 \%$ to $94 \%$ of the day [16]. For instance, objectively measured data from a large, nationally representative sample of Canadian children showed that, on average, 3- to 4-year-olds were sedentary for $436 \mathrm{~min} /$ day (7 h, $16 \mathrm{~min}$ ), which was roughly equivalent to $60 \%$ of their waking time [15].

The Canadian Sedentary Behaviour Guidelines were informed by a systematic review of the evidence that found that high levels of television (TV) time were associated with increased adiposity and reduced psychosocial health and cognitive development [2]. However, there was no evidence of benefits or harms for any other type of sedentary behaviour, for total sedentary time, or for patterns (e.g., frequency, interruptions) of sedentary time. This may be in part because only intervention and longitudinal studies were included in this earlier review [2]. This is a critical limitation because in recent years there has been a dramatic shift in the media landscape (e.g., evolving technologies including smartphones and tablets) [17], and because different types of sedentary behaviour (e.g., reading, sitting, playing video games) [18, 19] and different patterns of sedentary behaviour [20] may have different health effects. Evidence from large cross-sectional studies (with samples representative of the general population), together with new studies published since the original review, may provide additional insight.

In the intervening years, new systematic reviews have been conducted to investigate the relationships between sedentary behaviour and particular health indicators. For instance, Hinkley et al. found that too little evidence existed to draw conclusions regarding associations between sedentary behaviours and psychosocial wellbeing [21], and Carson et al. identified that different types of sedentary behaviour may have different effects on cognitive development in the early years of life (e.g., screen time may be detrimental, and reading beneficial) [18]. These recent reviews present focused summaries; however, no previous review has provided a balanced consideration of different types of sedentary behaviour and a range of holistic health indicators across study designs. Accordingly, a comprehensive review of the literature was needed in order to: 1) understand the health effects of sedentary behaviour in the early years, 2) inform and update population-level recommendations, and 3) identify research gaps and guide the design of future research and/or assist in the translation of current research to practice.

Therefore, the purpose of this study was to perform a systematic review that examined the relationships between sedentary behaviour and health indicators in children in their early years ( 0 to 4 years). An additional aim was to determine what doses of sedentary behaviour (i.e., duration, patterns [frequency, interruptions], and type) were associated with health indicators.

\section{Methods}

\section{Protocol and registration}

This systematic review was registered with the International Prospective Register of Systematic Reviews (PROSPERO; Registration no. CRD42016035270; available from http://www.crd.york.ac.uk/PROSPERO/display_record.asp?ID=CRD42016035270), and was conducted and reported following the Preferred Reporting Items for Systematic Reviews and Meta-Analyses (PRISMA) statement [22].

\section{Eligibility criteria}

The Population, Interventions, Comparisons, Outcomes, and Study design (PICOS) framework [23] was used to identify key study concepts in the research question, and to facilitate the search process. 


\section{Population}

The population of interest was apparently healthy children (i.e., general populations, including those with overweight and obesity; samples of clinical populations were ineligible) with a mean age of 1 month to 4.99 years (or, if no mean age was reported, samples described as: infants, toddlers, preschoolers, pre-elementary or preprimary school age) for at least one sedentary behaviour measurement point. Subgroups were defined as follows: infants, 1 month to 1 year; toddlers, 1.1 to 3.0 years; and preschoolers, 3.1 to 4.99 years.

\section{Intervention (exposure)}

The intervention/exposure was a specific measure of sedentary behaviour (e.g., TV viewing, video gaming, iPad/tablet/ touch-screen, smart phone, reading, puzzles, bouts, breaks, sedentary time, and "screen time" - defined as composite measures of screen use) obtained via objective (e.g., accelerometry) or subjective (e.g., proxy-report) methods. For infants, sedentary behaviour was operationally defined as any waking behaviour characterized by low energy expenditure (i.e., non-purposefully active) while restrained (e.g., in a stroller/pram, high chair, car seat/capsule), or when sedate (e.g., lying/sitting in a chair with little movement but not restrained). Time spent in the prone position ("tummy time") was not considered sedentary behaviour because this is deemed "physical activity" in this age group. For toddlers and preschoolers, sedentary behaviour was defined as any waking behaviour characterized by an energy expenditure of $\leq 1.5 \mathrm{METs}$ while in a sitting or reclining posture [1]. Studies defining sedentary behaviour as "physical inactivity" or "failing to meet physical activity guidelines" were excluded, because these definitions do not differentiate between sedentary behaviour and light-intensity physical activity. Studies of active video gaming exposures (e.g., Nintendo Wii ${ }^{\mathrm{TM}}$, Microsoft Kinect ${ }^{\mathrm{TM}}$, Sony's Playstation Move ${ }^{\mathrm{TM}}$ ) were excluded because these games may elicit energy expenditure > 1.5 METs [24], as were studies reporting background TV or screen access (e.g., TV is turned on, but not necessarily being watched by the child) because the child could be engaged in a non-sedentary behaviour. For experimental studies, interventions had to target sedentary behaviour exclusively and not multiple health behaviours (e.g., both sedentary behaviour and diet).

\section{Comparison}

Various durations, patterns (frequencies, interruptions), and types of sedentary behavior were used for comparison where available. A comparison or control group was not required.

\section{Outcomes (health indicators)}

Eight health indicators were chosen by expert consensus among a 22-member group with expertise in movement behaviours in children. The health indicators were selected given consideration of the literature (previous reviews; e.g., [2]) and of the importance of including a range of holistic health indicators (i.e., physical, psychological/social, and cognitive health). Four health indicators were identified as critical (primary) by expert consensus: (1) adiposity (e.g., \% body fat, weight status, waist circumference); (2) motor development (e.g., developmental milestones, gross/fine motor skills, locomotorobject control); (3) psychosocial health (e.g., depressive/ anxiety symptoms, prosocial behaviour, aggression, selfregulation); and (4) cognitive development (e.g., language development, attention, executive function). Four health indicators were identified as important (secondary) by expert consensus: (1) bone and skeletal health (e.g., bone mineral density, bone mineral content, skeletal area); (2) cardiometabolic health (e.g., blood pressure, insulin resistance, blood lipids); (3) fitness (cardiovascular, musculoskeletal); and (4) risks (injury)/ harm (e.g., plagiocephaly, torticollis).

\section{Study designs}

All study designs were considered. For longitudinal studies, any follow-up length was allowed as long as there was at least one measure of sedentary behaviour between the ages of 1 month to 4.99 years. For logistic reasons, and to maximize generalizability, minimum sample size requirements were imposed [25]; randomized controlled trials (RCTs) and non-randomized intervention studies were required to have at least 15 participants in at least one intervention group, and observational studies were required to have a minimum sample size of 100 participants. Published peer-reviewed original manuscripts and in-press manuscripts, in English or French, were eligible for inclusion. Grey literature (except for registered clinical trials) and conference abstracts were excluded.

\section{Information sources and search strategy}

The following databases were searched using the Ovid interface: MEDLINE (1946 to April 13, 2016), EMBASE (1980 to 2016 week 15), PsycINFO (1806 to April Week 1 2016), and CENTRAL (February 2016). PubMed was searched for any additional studies not yet indexed in MEDLINE (April 11, 2016). SPORTdiscus (1949 to April 14, 2016) and Communication Source (April 12, 2016) were searched using the EBSCOhost interface, and the Communications and Mass Media Collection was searched using Gale. The MEDLINE search strategy was created by a research librarian with expertise in systematic review searching and peer-reviewed by a second research librarian. The search was then adapted for other databases. No study design limits were applied, and searches were limited to English and French 
publications. Updates to all search strategies, limited to randomized controlled trials for logistical reasons, were performed on November 1, 2016, to capture any additional studies that had been published in the interim between the initial searches and the data synthesis. The search strategies are presented in Additional file 1. Trial registries were also searched (https://clinicaltrials.gov/ and http://www.who.int/ictrp/en/; October 11, 2016) for ongoing clinical trials, using search terms for the sedentary behaviour concept and age group of interest. The International Journal of Child-Computer Interaction was hand-searched, because this journal was not yet indexed in any of these databases.

Bibliographic records were extracted as text files from the Ovid, EBSCOHost, and Gale interfaces and imported into Reference Manager Software (Version 11; Thompson Reuters, San Francisco, CA, USA), where duplicate records were removed. Titles and abstracts of the remaining records were uploaded to DistillerSR (Evidence Partners, Ottawa, ON, Canada), a secure internet-based software, where they were screened against inclusion criteria independently by two reviewers. Exclusion by both reviewers was required for a study to be excluded at the title and abstract stage; all other studies passed to full-text article screening. Two independent reviewers examined all fulltext articles, and consensus was required for article inclusion in the review. Discrepancies between reviewers were resolved by discussion between themselves, or with the larger review team if needed. Relevant review articles identified during screening were also procured, and their reference lists manually checked for studies potentially missed by the search.

\section{Data extraction}

Data extraction forms were created by the study coordinators, and reviewed and piloted by the review team. Extraction was completed in Microsoft Excel by one reviewer and checked for accuracy by a second reviewer. Reviewers were not blinded to the authors or journals when extracting data. Information was extracted regarding important study characteristics (e.g., citation, study design, country, sample size, age, and sex of participants); exposure (i.e., sedentary behaviour characteristics [e.g., type, volume, duration, frequency, pattern, and measurement and/or description of sedentary behaviour intervention]); outcome/health indicators (e.g., measurement type); results (e.g., odds ratio, difference in means); and covariates included in the analyses (if applicable; e.g., diet, physical activity). If data were unavailable for extraction (e.g., reported only in a graph, or described as "data not shown"), the authors were contacted. If data were presented subdivided by sex, the data were extracted independently for each sex only if data pooled across sex were unavailable. If analyses were reported for any other subsets of data, results were extracted for only the analyses using the full sample. The results from finally adjusted models were extracted when studies presented multiple models. Study findings were considered statistically significant at $p<0.05$.

\section{Risk of bias and study quality assessment}

The risk of bias was systematically evaluated in each primary research study using the methods described in the Cochrane Handbook [26]. All individual studies were assessed for the following potential sources of bias: selection bias, performance bias, detection bias, attrition bias, reporting bias, and other sources of bias (see Poitras et al. [25] for details).

The quality of evidence for each health indicator by each type of study design was assessed using the Grading of Recommendations, Assessment, Development and Evaluation (GRADE) framework [27]. The "quality of evidence" is the level of confidence in the estimate of effect. As such, the higher the quality of the evidence, the greater the confidence in the findings, and the lower the quality, the more likely it is that future research will change the level of confidence in the estimates and change the estimates themselves. According to GRADE, there are four levels of quality ("high", "moderate", "low", and "very low"); evidence quality ratings start at "high" for randomized studies and at "low" for all other studies. The quality of evidence is downgraded if there are limitations across studies due to serious risk of bias, inconsistency (e.g., unexplained heterogeneity in the direction of the effect), indirectness (e.g., differences between the population, intervention and/or outcomes in included studies and those of interest, such as a surrogate measure instead of a direct measure of an outcome), or imprecision (e.g., wide confidence intervals that lead to uncertainty about the true magnitude of the effect) [28]. If there is no reason to downgrade, the quality of evidence can be upgraded if there is a large effect size, there is a dose-response gradient, or an effect is detected in the presence of plausible confounders or other biases that would decrease an apparent treatment effect [29].

In the present review, the overall quality of evidence for each study design within each health indicator was evaluated by two independent reviewers and verified by the larger review team. The review team decided a priori not to downgrade for risk of bias if the only potential sources of bias identified were use of a convenience sample or lack of exposure/outcome blinding, as in previous movement behaviour systematic reviews $[25,30]$.

\section{Synthesis of results}

Meta-analyses were planned if data were sufficiently homogeneous in terms of statistical, clinical, and 
methodological characteristics. If meta-analyses were not possible, qualitative syntheses structured around the health indicator and type of sedentary behaviour were conducted, with all studies weighted equally, and the results presented narratively. Results were presented in "evidence profile" tables by outcome (health indicator) as per the GRADE framework (see Guyatt et al. [27] for details). For the purposes of this review, sedentary behaviours were grouped into three categories: 1) objectively measured sedentary time, 2) screen-based sedentary behaviours, and 3) other sedentary behaviours (e.g., reading, storytelling).

\section{Results}

\section{Description of studies}

A total of 10,830 records were identified in the initial searches, and an additional 11 were identified by checking the reference lists of review articles (Fig. 1). After de-duplication, 8915 records remained. In the search update, an additional 106 records were identified (making a total of 10,936), and 101 of these remained after de-duplication. No relevant records were identified in the Trial Registry searches. After screening the 9016 titles and abstracts (from the initial and updated searches), 334 full-text articles were obtained for further review. Reasons for exclusion were: not in English or French language $(n=1)$, review paper $(n=2)$, sedentary behaviour included only as a covariate or outcome and not as the exposure $(n=2)$, sedentary behaviour defined as "failing to meet physical activity guidelines" $(\mathrm{n}=2)$, sedentary behaviour exposure included background screens $(n=3)$, intervention did not target sedentary behaviour specifically/exclusively $(n=9)$, not original research $(n=9)$, no sedentary behaviour exposure $(n=$ 9), sample size $(n=15)$, did not assess the relationship between sedentary behaviour and a relevant health indicator $(n=77)$, participants were not within appropriate age range $(n=92)$, and other $(n=17$; e.g., comparator

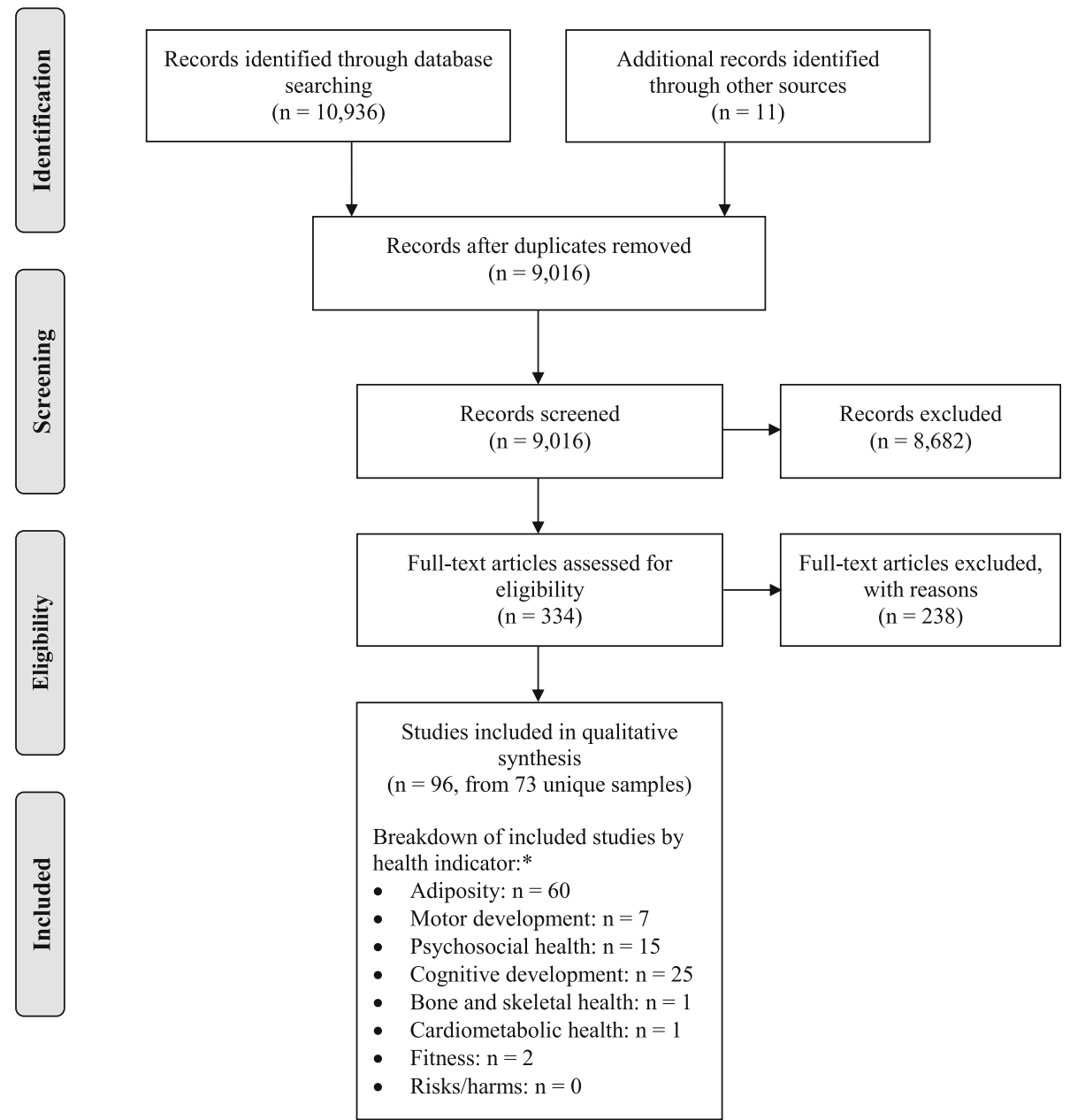

Fig. 1 PRISMA flow diagram for the identification, screening, eligibility, and inclusion of studies. ${ }^{*}$ Note that the numbers for each health indicator do not sum to the total number of included studies because more than one health indicator was reported in some studies 
was the same "dose" of sedentary behaviour with different content, predatory publisher and problems with data such as incongruent values in text and tables). Some studies were excluded for multiple reasons. A total of 96 studies (from 73 unique samples) met the inclusion criteria (Fig. 1).

Detailed findings for the individual 96 studies are presented in Additional file 2: Tables S1-S7 and summarized in Tables 1, 2, 3, 4, 5, 6, 7 and 8. Data across studies involved 195,430 participants (147,752 from 73 unique samples), ranging from 103 [31] to 50,589 [32] participants. Participants from one study were not included in this sample size calculation because the sample size for the age group of interest was not reported [33]. Studies were conducted in 33 different countries, but were most commonly conducted in the United States $(n=44)$, Belgium $(n=7)$, Canada $(n=7)$, Australia $(n=6)$, Germany $(n=5)$, and the Netherlands $(n=5)$, with four or fewer studies from all other countries (Additional file 2: Tables S1-S7). The approximate baseline age ranged from 0.3 to 4.95 years. One study used an experimental design (randomized controlled trial); the remaining 95 studies used observational designs, including case-control $(n=3)$, longitudinal $(n=25)$, longitudinal with additional cross-sectional analyses $(n=5)$, and cross-sectional $(n=62)$.

\section{Quality of evidence}

Overall, the quality of evidence ranged from "very low" to "moderate" across study designs and health indicators. The most common reason for downgrading the quality of evidence was because of a serious risk of bias that reduced the level of confidence in the observed effects. Common sources of bias included: not accounting for potentially important confounders or mediating factors (e.g., diet); the use of potentially inappropriate measurement tools (e.g., exposure or outcome measures with unknown reliability and/or validity); and an unknown amount of, or reasons for, missing data. The quality of evidence was not upgraded in any instance. For specific details regarding the quality of evidence by study design and health indicator, see Tables 1, 2, 3, 4, 5, 6 and 7.

\section{Data synthesis}

Meta-analyses could not be performed because of heterogeneity in the sedentary behaviour exposure and health indicators (statistical, clinical, and methodological). Instead, narrative syntheses are presented. Unless otherwise stated, results did not differ by sex, age, or specific sub-indicator within the eight health indicator categories. Within each health indicator, results are presented first by study design, then by type of sedentary behaviour exposure (objectively measured sedentary time, screen-based sedentary behaviours, and other sedentary behaviours), and finally by sub-indicator (i.e., specific measures of the eight health indicators). The reader is referred to the Additional file 2: Tables S1-S7 for statistic values and additional details.

\section{Critical (primary) health indicators Adiposity}

The relationships between sedentary behaviour and adiposity were examined in 60 studies (see Table 1 and Additional file 2: Table S1) [31-90]. Study designs were: randomized controlled trial $(n=1)$ [34], longitudinal $(n=$ 13) $[33,45,54,81-90]$, case-control $(n=2)[35,36]$, and cross-sectional design or also reported cross-sectional findings $(n=47)$ [31-33, 37-80]. Indicators of adiposity (e.g., body mass index $[\mathrm{BMI}]$ ) were measured objectively (e.g., measured by dual-energy X-ray absorptiometry) or assessed subjectively (e.g., parent-reported height and weight; see Table 1 for summary of measures). The quality of evidence ranged from "very low" to "moderate" across study designs (Table 1).

In the randomized controlled trial of an intervention to reduce screen time, screen time was significantly lower for preschoolers in the intervention versus control group at 2, 6, and 9 months post-intervention [34]. BMI $\mathrm{z}$-scores were not different between the intervention and control groups at baseline or 9-month follow-up, but BMI z-scores increased in both groups [34] (Additional file 2: Table S1).

Among the 13 longitudinal studies, sedentary behaviour was assessed from age $\sim 9$ months to 4.95 years as screenbased (i.e., computer time, frequency of playing computer games, time watching DVDs, TV time, and total screen time) or other sedentary behaviours (i.e., time spent in the car or in baby seats). Adiposity indicators were assessed between $\sim 1.25$ and 12 years follow-up.

For screen-based sedentary behaviours, computer time [85], and frequency of playing computer games [82] at age 4.8 years were not associated with total fat mass or lean mass, or weight status, at $\sim 6$ and 12 years of follow-up respectively. Time watching DVDs at ages $\sim 3-4$ years was unfavourably associated with weight status at kindergarten entry [83]. Total screen time in toddlers was unfavourably associated with weight status at preschool or school age in $2 / 3$ studies $[33,84]$. In the third study, total screen time was not associated with weight status [87].

Ten longitudinal studies examined the relationships between TV time (at ages ranging from $\sim 6$ months to 4.8 years) and adiposity indicators at $\sim 1.5$ to 12 years of follow-up. Of these, unfavourable associations were reported in $6 / 10$ studies [33, 54, 81, 83, 88, 90], null associations in $1 / 10$ studies [86], and mixed unfavourable and null associations in 3/10 studies [82, 85, 89]. Specifically, TV time was prospectively unfavourably associated with these adiposity indicators: BMI z-score in $1 / 1$ studies [88], BMI in $2 / 3$ studies [ 54,90 ], \% change 


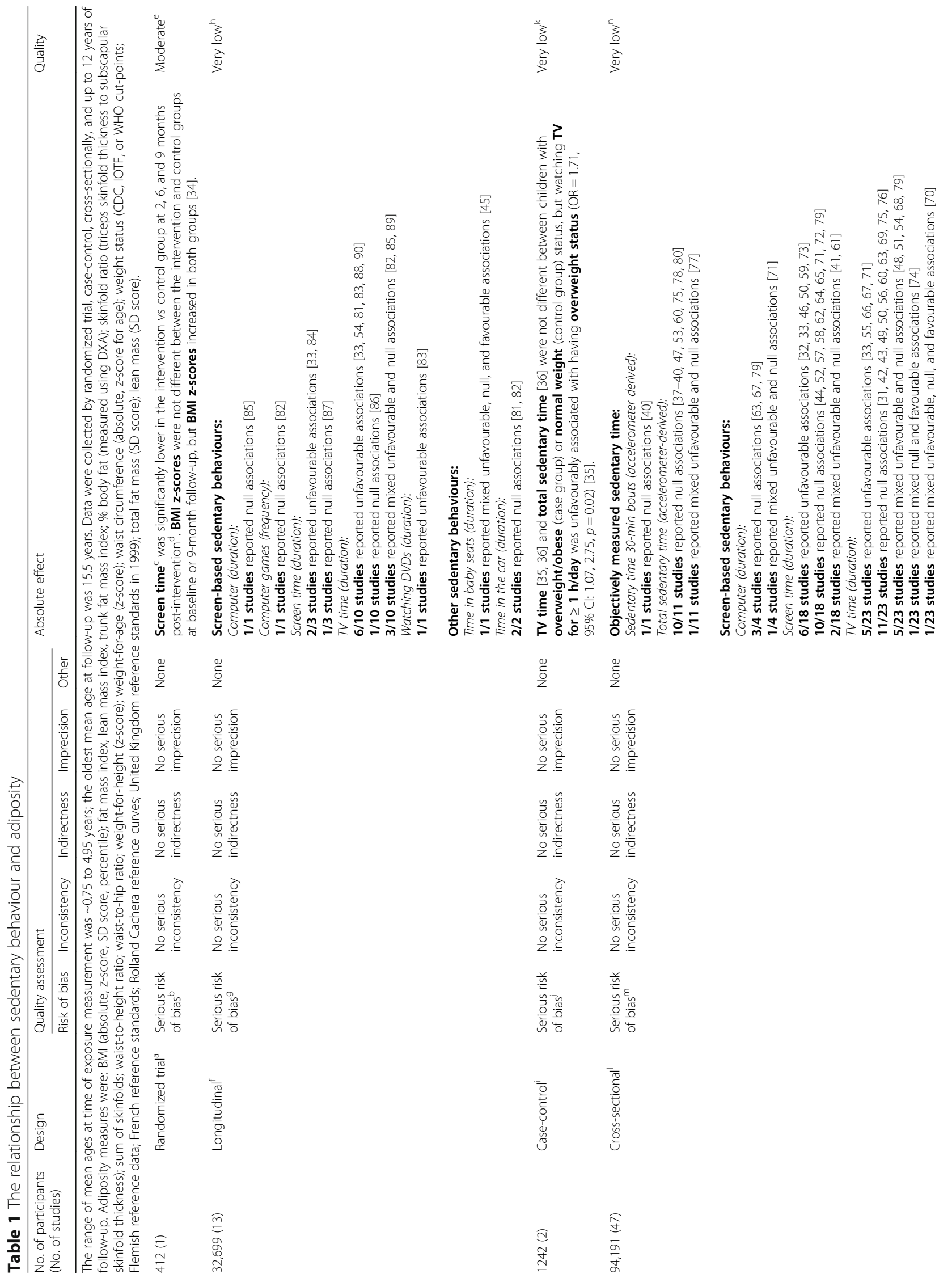




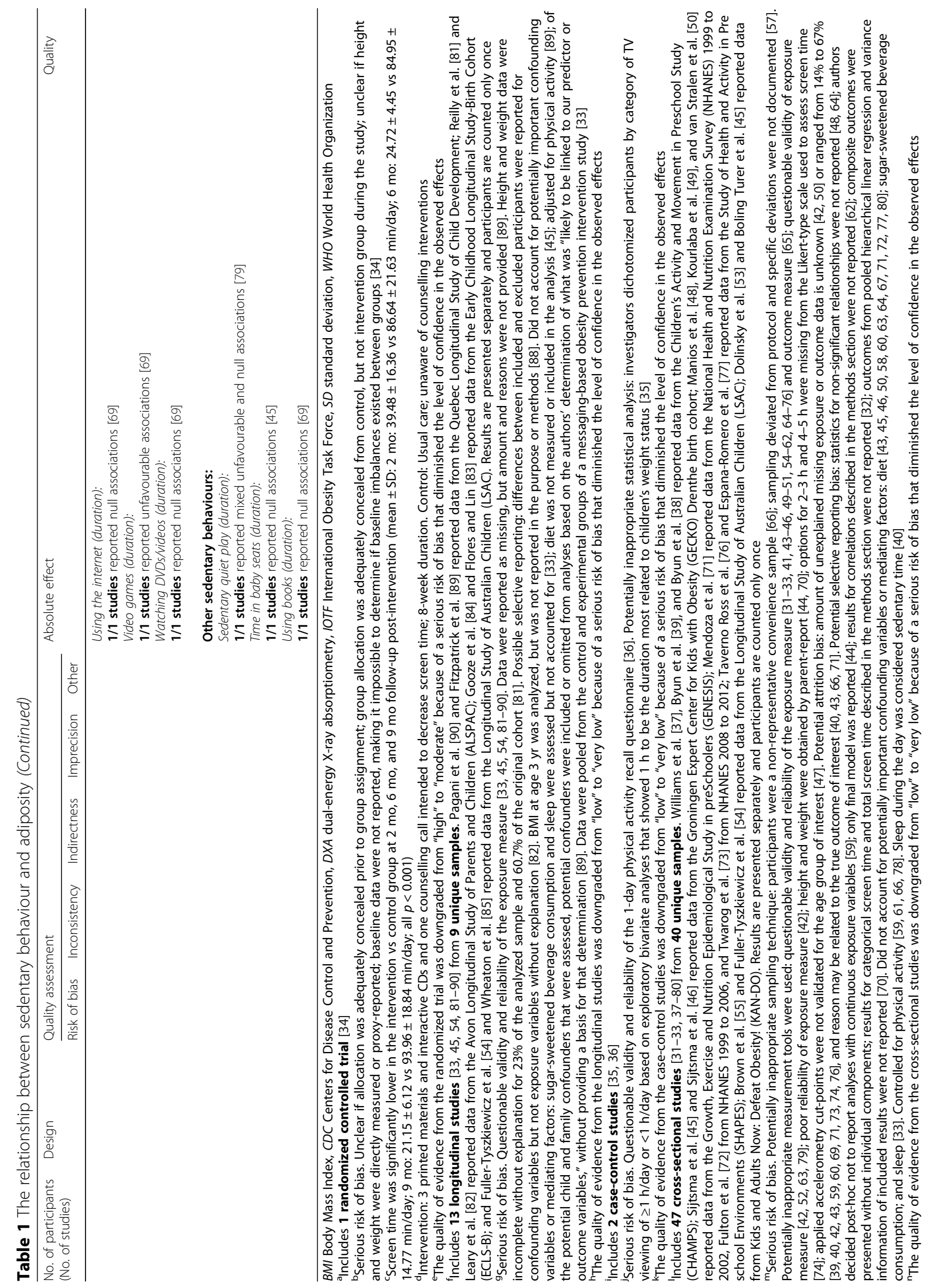



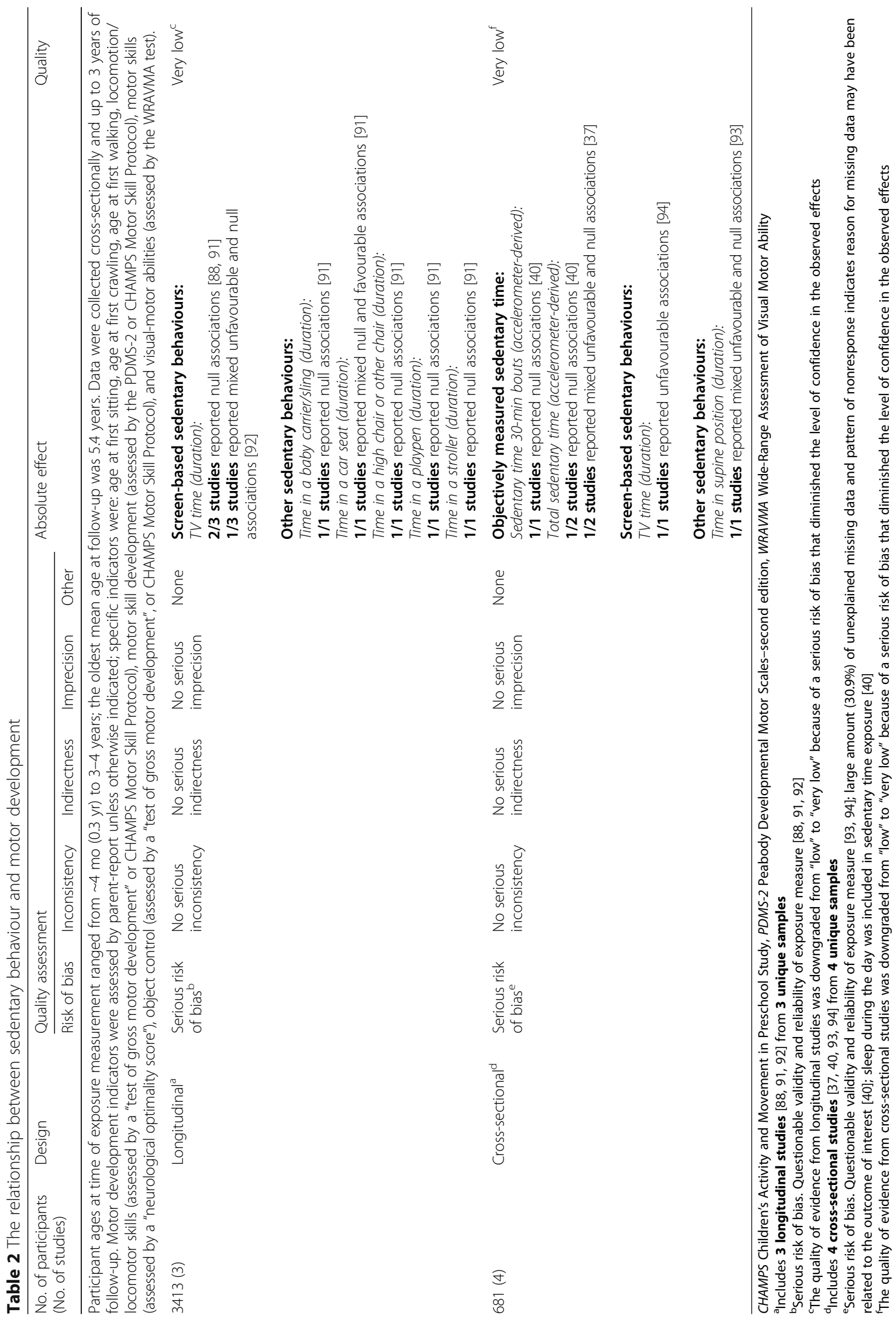


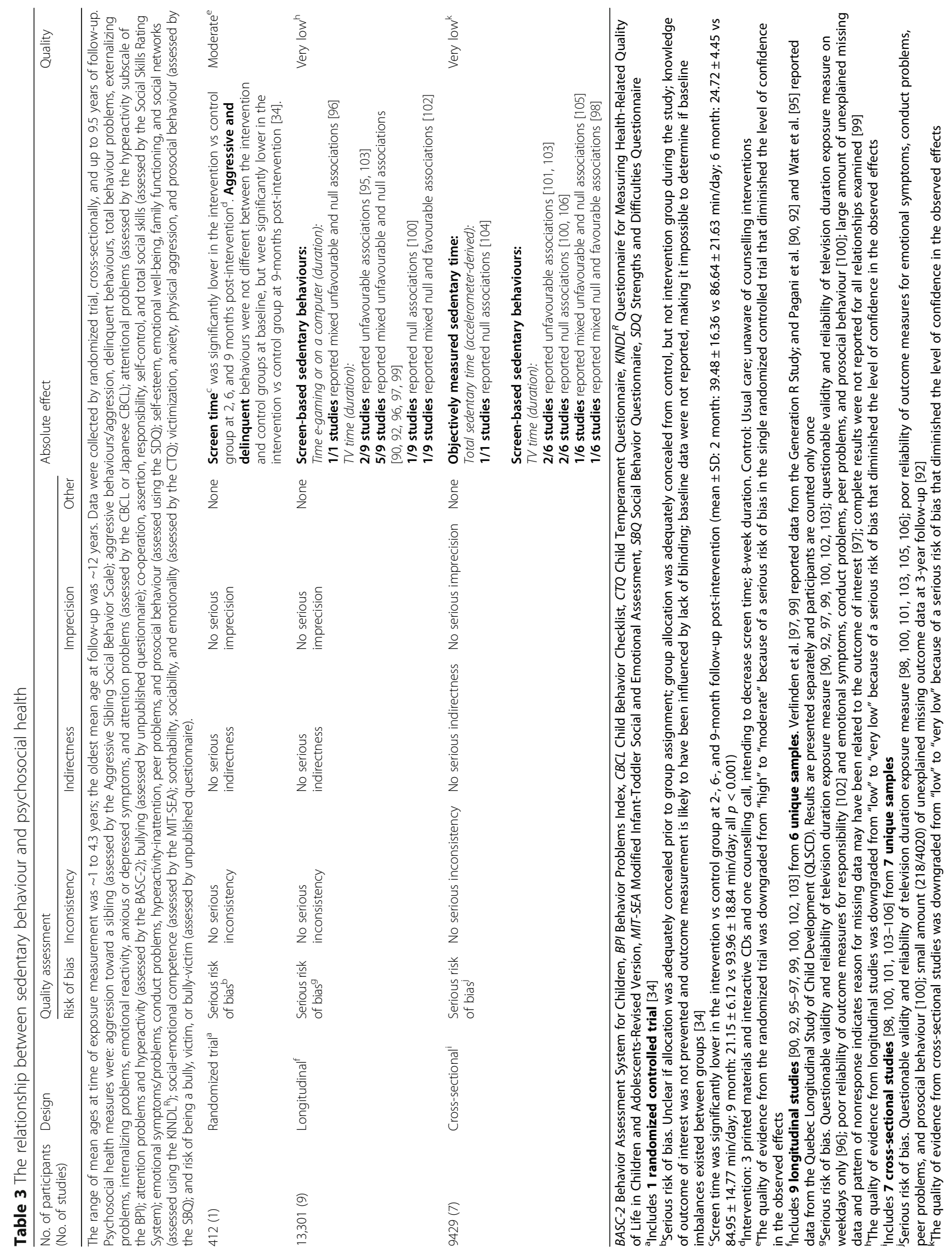




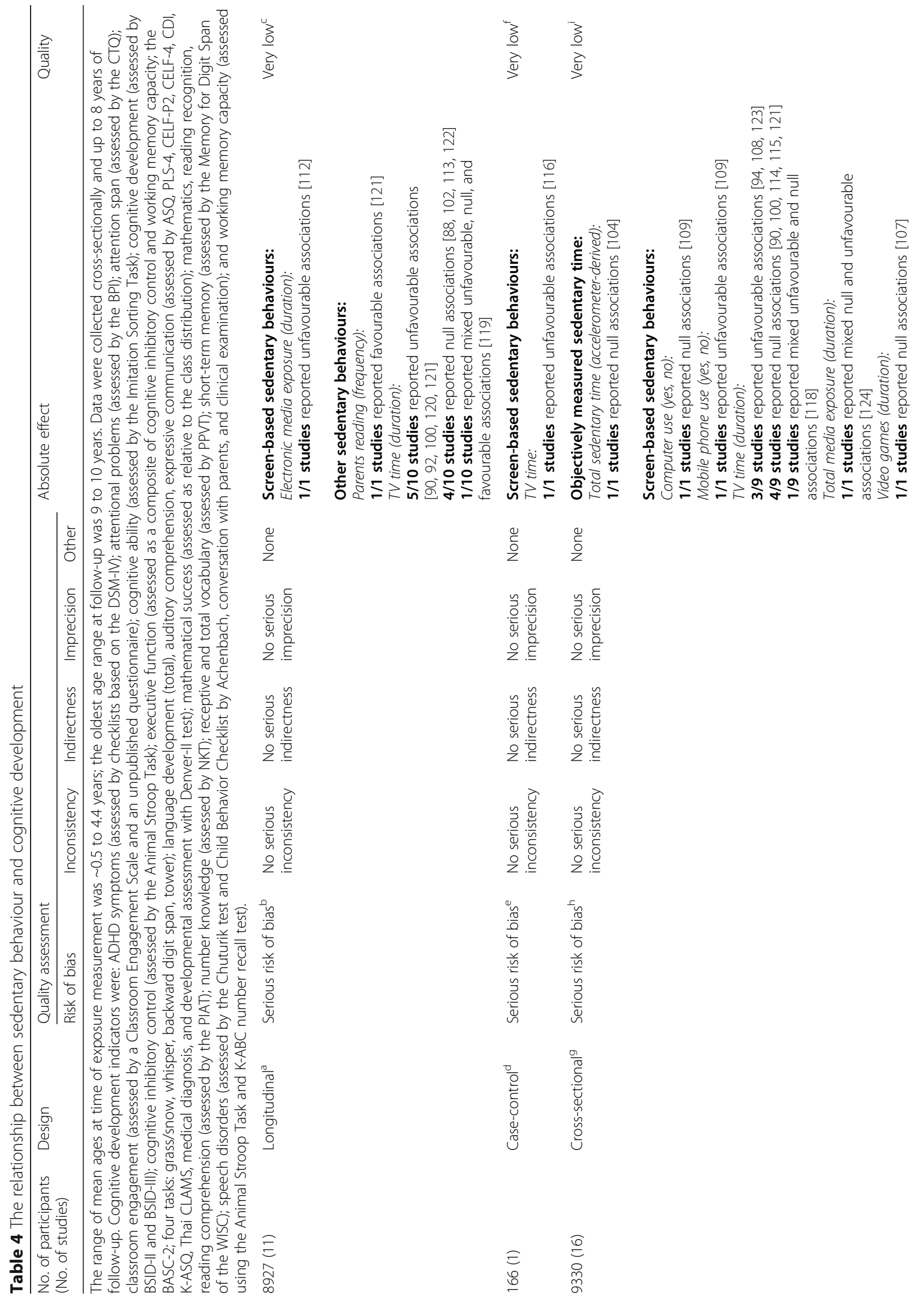




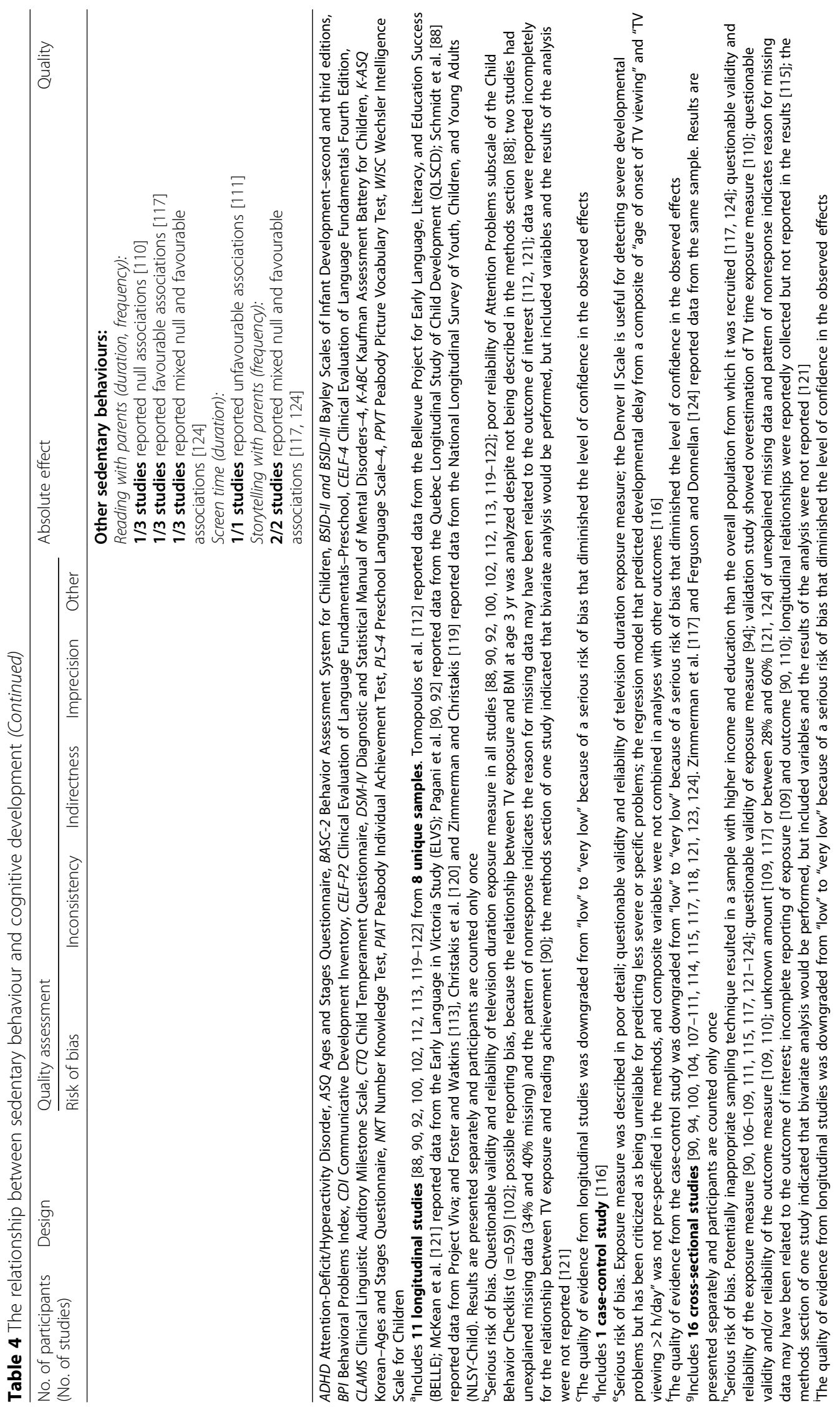


Table $\mathbf{5}$ The relationship between sedentary behaviour and bone and skeletal health

\begin{tabular}{|c|c|c|c|c|c|c|c|}
\hline \multirow{2}{*}{$\begin{array}{l}\text { No. of participants } \\
\text { (No. of studies) }\end{array}$} & \multirow[t]{2}{*}{ Design } & \multicolumn{4}{|c|}{ Quality assessment } & \multirow[t]{2}{*}{ Absolute effect } & \multirow[t]{2}{*}{ Quality } \\
\hline & & Risk of bias & Inconsistency & Indirectness & Imprecision & & \\
\hline \multicolumn{8}{|c|}{ The mean age was 4.4 years. Data were collected cross-sectionally. Bone and skeletal health were assessed objectively using quantitative ultrasound. } \\
\hline $1512(1)$ & Cross-sectional ${ }^{a}$ & $\begin{array}{l}\text { Serious risk } \\
\text { of bias }^{b}\end{array}$ & $\begin{array}{l}\text { No serious } \\
\text { inconsistency }\end{array}$ & $\begin{array}{l}\text { No serious } \\
\text { indirectness }\end{array}$ & $\begin{array}{l}\text { Serious } \\
\text { imprecision }^{c}\end{array}$ & $\begin{array}{l}\text { Objectively measured sedentary time: } \\
\text { After adjusting for MVPA, accelerometer-derived sedentary } \\
\text { time was no longer significantly associated with bone } \\
\text { stiffness index (SI) in preschool children ( } \beta=-0.37 \text {; } \\
\left.R^{2}=19 \% ; p=0.28\right)[125] \text {. } \\
\text { Screen-based sedentary behaviours: } \\
\text { There was no association between parent-reported screen } \\
\text { time and } \mathbf{S I}\left(\beta=-0.04 ; R^{2}=18.4 \% ; p=0.50\right)[125] \text {. }\end{array}$ & Very low ${ }^{d}$ \\
\hline
\end{tabular}

MVPA moderate-to-vigorous physical activity, SI bone stiffness index

ancludes 1 cross-sectional study that reported data from the Identification and prevention of dietary- and lifestyle-induced health effects in children and infants (IDEFICS) sample [125]

bSerious risk of bias. Study participants were selected by "judgment sample"; questionable validity and reliability of subjective and objective exposure measures, and of quantitative ultrasound for measurement of bone stiffness in children [125]

'Serious imprecision. It was not possible to estimate the precision of the findings since the study did not provide a measure of variability in the results

'The quality of evidence from the cross-sectional study was downgraded from "low" to "very low" because of: (1) a serious risk of bias that diminished the level of confidence in the observed effects, and (2) serious imprecision

in $\mathrm{BMI}$ and \% change in waist-to-height ratio in $1 / 1$ studies [33], fat mass in $1 / 1$ studies [82], and weight status in 2/2 studies [81, 83] (Additional file 2: Table S1). TV time at age $\sim 3$ years was not associated with the rate of weight gain from ages 3 to 5 years [86]. TV time at age 2.4 years was not associated with waist circumference at age 10.15 years, but the change in TV time from ages 2.4 to 4.4 years was unfavourably associated with waist circumference at age 10.15 years [89]. TV time at age 3.2 years was unfavourably associated with fat mass at age 15 years.

Regarding other sedentary behaviours, types of sitting were examined in three longitudinal studies. Among preschoolers, time in the car was not prospectively associated with adiposity indicators in $2 / 2$ studies [82, 85]; however, among infants there were mixed unfavourable, null, and favourable associations between time in baby seats and adiposity indicators [45]. Specifically, time in baby seats at age $\sim 9$ months was unfavourably associated with a change in weight-for-height and change in weight-for-age from $\sim 9$ months to 2 years, was not associated with weight-for-height or weight-for-age at age $\sim 2$ years, and was favourably associated with waist circumference-for-age at age $\sim 2$ years and change in waist circumference-for-age from $\sim 9$ months to 2 years [45] (Additional file 2: Table S1).
In the two case-control studies, TV time [35, 36] and total sedentary time (assessed by one-day parent-recall) [36] were not significantly different between preschoolers with overweight/obese (case group) or normalweight (control group) status, but watching TV for $\geq 1 \mathrm{~h} /$ day was unfavourably associated with having overweight status [35] (Additional file 2: Table S1).

Among the 47 cross-sectional studies, sedentary behaviour was assessed as accelerometer-derived sedentary time, screen-based (i.e., computer time, time playing inactive video games, using the internet, watching DVDs/videos, TV time, and total screen time), or other sedentary behaviours (i.e., sedentary quiet play, and time in the car or in baby seats).

The relationships between accelerometer-derived sedentary time and adiposity indicators in toddlers and preschoolers were examined in 11 cross-sectional studies; null associations were reported in 10/11 studies [37-40, 47, 53, $60,75,78,80]$ and mixed unfavourable and null associations in 1/11 studies [77] (Additional file 2: Table S1). Specifically, total sedentary time was not associated with: \% body fat, fat mass index, trunk fat mass index, or lean mass index in 1/1 studies [78]; BMI in 1/1 studies [75]; BMI zscore in 4/4 studies [37-39,47]; and weight status in $4 / 4$ studies $[40,53,60,80]$ (Additional file 2: Table S1). Total sedentary time was not associated with BMI z-score

Table 6 The relationship between sedentary behaviour and cardiometabolic health

\begin{tabular}{|c|c|c|c|c|c|c|c|}
\hline \multirow{2}{*}{$\begin{array}{l}\text { No. of participants } \\
\text { (No. of studies) }\end{array}$} & \multirow[t]{2}{*}{ Design } & \multicolumn{4}{|l|}{ Quality assessment } & \multirow[t]{2}{*}{ Absolute effect } & \multirow[t]{2}{*}{ Quality } \\
\hline & & Risk of bias & Inconsistency & Indirectness & Imprecision & & \\
\hline \multicolumn{8}{|c|}{ The mean age was 3.1 years. Data were collected cross-sectionally. Cardiometabolic health was assessed using an objective measure of blood pressure. } \\
\hline $276(1)$ & Cross-sectional $^{\mathrm{a}}$ & Serious risk of bias ${ }^{b}$ & $\begin{array}{l}\text { No serious } \\
\text { inconsistency }\end{array}$ & $\begin{array}{l}\text { No serious } \\
\text { indirectness }\end{array}$ & $\begin{array}{l}\text { No serious } \\
\text { imprecision }\end{array}$ & $\begin{array}{l}\text { Screen-based sedentary behaviours: } \\
\text { Watching TV for } \geq \mathbf{2} \text { h/day was not associated with } \\
\text { high blood pressure (compared to }<2 \mathrm{~h} / \text { day, } \\
\text { Prevalence Ratio }=0.9,95 \% \mathrm{Cl}: 0.5,1.4, p=0.568 \text { ) [126]. }\end{array}$ & Very low ${ }^{c}$ \\
\hline
\end{tabular}

Includes 1 cross-sectional study [126]

bSerious risk of bias. Unknown reliability and validity of the exposure measure [126]

"The quality of evidence from the cross-sectional study was downgraded from "low" to "very low" because of a serious risk of bias that diminished the level of confidence in the observed effects 
Table 7 The relationship between sedentary behaviour and fitness

\begin{tabular}{|c|c|c|c|c|c|c|c|}
\hline \multirow{2}{*}{$\begin{array}{l}\text { No. of participants } \\
\text { (No. of studies) }\end{array}$} & \multirow[t]{2}{*}{ Design } & \multicolumn{4}{|c|}{ Quality assessment } & \multirow[t]{2}{*}{ Absolute effect } & \multirow[t]{2}{*}{ Quality } \\
\hline & & Risk of bias & Inconsistency & Indirectness & Imprecision & & \\
\hline \multicolumn{8}{|c|}{$\begin{array}{l}\text { The mean age at exposure measurement ranged from } \sim 29 \text { to } 53 \text { months ( } 2.4 \text { to } 4.4 \text { yr). Data were collected longitudinally up to } 8 \text { years of follow-up. Fitness was } \\
\text { assessed as: lower body explosive strength (standing long jump) and fitness level (parent-report level relative to other children). }\end{array}$} \\
\hline $1314(2)$ & Longitudinal $^{\mathrm{a}}$ & $\begin{array}{l}\text { Serious risk of } \\
\text { bias }^{b}\end{array}$ & $\begin{array}{l}\text { No serious } \\
\text { inconsistency }\end{array}$ & $\begin{array}{l}\text { Serious } \\
\text { indirectness }^{c}\end{array}$ & $\begin{array}{l}\text { No serious } \\
\text { imprecision }\end{array}$ & $\begin{array}{l}\text { Screen-based sedentary behaviours: } \\
\text { Higher TV time (hr/day) at age } \sim 29 \text { mo } \\
\text { was unfavourably associated with standing } \\
\text { long-jump performance }(\mathrm{cm}) \text { at age } 97.8 \mathrm{mo} \\
(\mathrm{B}=-0.361 ; 95 \% \mathrm{Cl}:-0.576,-0.145 ; p<0.001)[89] \\
\text { and physical fitness level }(\mathrm{scale} \text { from }-2 \text { to } 2) \text { in Grade } 4 \\
(\beta=-0.09, \mathrm{SE}=0.0004 ; \mathrm{B}=-0.01,95 \% \mathrm{Cl}:-0.002,-0.02 ; \\
p<0.01)[90] \text {. } \\
\text { A greater increase in TV time (hr/week) between age } \sim 29 \\
\text { and } \sim 53 \text { months was unfavourably associated with standing } \\
\text { long-jump performance }(\mathrm{cm}) \text { at age } 97.8 \text { month }(\mathrm{B}=-0.285 ; \\
95 \% \mathrm{Cl}:-0.436,-0.134 ; p<0.01) \text { [89] and physical fittess level } \\
(\mathrm{scale} \text { from }-2 \text { to } 2, \text { relative to other children) in Grade } 4 \\
(\beta=-0.10, \mathrm{SE}=0.0003, p<0.01)[90] \text {. }\end{array}$ & Very low \\
\hline
\end{tabular}

Includes 2 longitudinal studies [89, 90] from 1 unique sample (QLSCD)

${ }^{b}$ Serious risk of bias. Questionable reliability and validity of the exposure [89, 90] and outcome [90] measures; large unexplained loss to follow-up and unclear if included participants differed from missing participants [89]; controlled for physical activity [89, 90]

'Serious indirectness. Differences between outcomes of included studies and those of interest; only one study reported a measure of lower-body musculoskeletal fitness (lower-body strength assessed by standing long-jump performance) [89], and one study reported an indirect measure of physical fitness [90]. No studies reported direct measures of total body musculoskeletal or cardiovascular fitness

"The quality of evidence from the longitudinal studies was downgraded from "low" to "very low" because of: 1) a serious risk of bias that diminished the level of confidence in the observed effects, and 2) indirectness of the comparisons being assessed

percentile or waist circumference, but was associated with waist circumference percentile in girls (not boys) in $1 / 1$ studies [77]. Accelerometer-derived sedentary time in 30min bouts was not associated with weight status [40].

For screen-based sedentary behaviours, time playing inactive video games was unfavourably associated with preschoolers' BMI percentile, but using the internet and watching DVDs/videos were not cross-sectionally associated with BMI percentile [69] (Additional file 2: Table S1). Computer time was not associated with preschoolers' weight status in $4 / 4$ studies [63, 67, 71, 79], but was unfavourably associated with sum of skinfold thicknesses in $1 / 1$ studies [71].

The relationships between total screen time and adiposity indicators were examined in 18 cross-sectional studies; unfavourable associations were reported in $6 / 18$ studies [32, 33, 46, 50, 59, 73], null associations in 10/18 studies $[44,52,57,58,62,64,65,71,72,79]$, and mixed unfavourable and null associations in 2/18 studies [41, 61] (Additional file 2: Table S1). Of these, screen time was unfavourably associated with: sum of skinfold thicknesses in $0 / 1$ studies, waist-to-height ratio in $1 / 1$ studies [33], BMI in $2 / 2$ studies $[46,50]$, and at least one measure of weight status in $6 / 16$ studies $[32,33,41,59,61$, 73]. Only one of these studies was in infants (no association between screen time and weight status [58]); the rest were in toddlers and preschoolers.

The relationships between TV time and adiposity indicators in toddlers and preschoolers were examined in 23 cross-sectional studies; unfavourable associations were reported in 5/23 studies [33, 55, 66, 67, 71], null associations in 11/23 studies [31, 42, 43, 49, 50, 56, 60, 63, 69, $75,76]$, mixed unfavourable and null associations in 5/
23 studies [48, 51, 54, 68, 79], mixed null and favourable associations in $1 / 23$ studies [74], and mixed unfavourable, null, and favourable associations in $1 / 23$ studies [70] (Additional file 2: Table S1). Of these, TV time was unfavourably associated with: waist-to-hip ratio in $0 / 1$ studies, waist-to-height ratio in $1 / 1$ studies [33], triceps skinfold thickness in $0 / 1$ studies, waist circumference in $0 / 2$ studies, sum of skinfolds in $1 / 3$ studies [71], BMI percentile in $0 / 1$ studies, BMI in $2 / 11$ studies $[51,54]$, and at least one measure of weight status in $9 / 13$ studies [33, 48, 55, 66-68, 70, 71, 79]. Weekday (but not weekend) TV time was favourably associated with the ratio of triceps to subscapular skinfold thickness (representing limb-to-trunk adiposity ratio) in girls but not boys in $1 / 1$ studies [74]. TV time was favourably associated with BMI z-score in boys but not girls in $1 / 1$ studies [70] (Additional file 2: Table S1).

Regarding other sedentary behaviours, infants' time in baby seats was not cross-sectionally associated with weight-for-height/age or waist circumference-for-age [45]. Among preschoolers, time using books [69] was not associated with BMI percentile [69]. Sedentary quiet play (defined as "e.g., looking into books, playing with blocks, playing with dolls, drawing, construction") on weekdays or weekend days was not associated with weight status in boys [79]. In girls, sedentary quiet play on weekend days (but not weekdays) was unfavourably associated with weight status [79].

\section{Motor development}

The relationships between sedentary behaviour and motor development were examined in seven studies (see Table 2 and Additional file 2: Table S2) [37, 40, 88, 91-94]. Study 
Table 8 High-level summary of findings by health indicator

\begin{tabular}{|c|c|c|c|}
\hline Health indicator & Number of studies & Quality of evidence & $\begin{array}{l}\text { Summary of findings: Number of studies reporting unfavourable/null/favourable } \\
\text { associations with at least one health indicator measure by SB type }\end{array}$ \\
\hline \multicolumn{4}{|l|}{ Critical } \\
\hline \multirow[t]{13}{*}{ Adiposity } & 60 & Very low to moderate & Objectively measured sedentary time: \\
\hline & & & Sedentary time in 30-min bouts (accelerometer-derived): null (1) \\
\hline & & & Total sedentary time (accelerometer-derived): unfavourable (1), null (12) \\
\hline & & & Screen-based sedentary behaviours: \\
\hline & & & Computer (duration, frequency): unfavourable (1), null (6) \\
\hline & & & Internet (duration): null (1) \\
\hline & & & Total screen time (duration): unfavourable (9), null (14) \\
\hline & & & TV time (duration): unfavourable (20), null (24), favourable (2) \\
\hline & & & Video games (duration): unfavourable (1) \\
\hline & & & Other screens (DVDs/videos; duration): unfavourable (1), null (1) \\
\hline & & & Other sedentary behaviours: \\
\hline & & & Reading (duration): null (1) \\
\hline & & & $\begin{array}{l}\text { Sitting (baby seats, car, sedentary quiet play; duration): unfavourable (2), } \\
\text { null (4), favourable (1) }\end{array}$ \\
\hline \multirow[t]{8}{*}{ Motor development } & 7 & Very low & Objectively measured sedentary time: \\
\hline & & & Sedentary time in 30-min bouts (accelerometer-derived): null (1) \\
\hline & & & Total sedentary time (accelerometer-derived): unfavourable (1), null (2) \\
\hline & & & Screen-based sedentary behaviours: \\
\hline & & & TV time (duration): unfavourable (2), null (3) \\
\hline & & & Other sedentary behaviours: \\
\hline & & & $\begin{array}{l}\text { Sitting (baby carrier/sling, car seat, high chair/other chair, playpen, stroller; } \\
\text { duration): null (1), favourable (1) }\end{array}$ \\
\hline & & & Supine position (duration): unfavourable (1), null (1) \\
\hline \multirow[t]{6}{*}{ Psychosocial health } & 15 & Very low to moderate & Objectively measured sedentary time: \\
\hline & & & Total sedentary time (accelerometer-derived): null (1) \\
\hline & & & Screen-based sedentary behaviours: \\
\hline & & & Computer (duration): unfavourable (1), null (1) \\
\hline & & & Total screen time (duration): unfavourable (1) \\
\hline & & & TV time (duration): unfavourable (9), null (11), favourable (2) \\
\hline \multirow[t]{9}{*}{ Cognitive development } & 25 & Very low & Objectively measured sedentary time: \\
\hline & & & Total sedentary time (accelerometer-derived): null (1) \\
\hline & & & Screen-based sedentary behaviours: \\
\hline & & & Computer (yes, no): null (1) \\
\hline & & & Mobile phone use (yes, no): unfavourable (1) \\
\hline & & & Total screen time (duration): unfavourable (1) \\
\hline & & & TV time (duration): unfavourable (11), null (10), favourable (1) \\
\hline & & & Video games (duration): null (1) \\
\hline & & & $\begin{array}{l}\text { Other screens (total or electronic media exposure; duration): } \\
\text { unfavourable (2), null (1) }\end{array}$ \\
\hline
\end{tabular}


Table 8 High-level summary of findings by health indicator (Continued)

\begin{tabular}{|c|c|c|c|}
\hline Health indicator & Number of studies & Quality of evidence & $\begin{array}{l}\text { Summary of findings: Number of studies reporting unfavourable/null/favourable } \\
\text { associations with at least one health indicator measure by SB type }\end{array}$ \\
\hline & & & Other sedentary behaviours: \\
\hline & & & Reading (duration, frequency): null (2), favourable (3) \\
\hline & & & Storytelling with parents (frequency): null (2), favourable (2) \\
\hline \multicolumn{4}{|l|}{ Important } \\
\hline \multirow[t]{4}{*}{ Bone and skeletal health } & 1 & Very low & Screen-based sedentary behaviours: \\
\hline & & & Screen time (duration): null (1) \\
\hline & & & Objectively measured sedentary time: \\
\hline & & & Total sedentary time (accelerometer-derived): null (1) \\
\hline \multirow[t]{2}{*}{ Cardiometabolic health } & 1 & Very low & Screen-based sedentary behaviours: \\
\hline & & & TV time (duration): null (1) \\
\hline \multirow[t]{2}{*}{ Fitness } & 2 & Very low & Screen-based sedentary behaviours: \\
\hline & & & TV time (duration): unfavourable (2) \\
\hline Risks / harms & 0 & N/A & N/A \\
\hline
\end{tabular}

${ }^{a}$ Note that the number of studies reporting unfavourable/null/favourable associations does not sum to the total number of studies for a given indicator since some studies reported mixed associations. N/A: not applicable

designs were: longitudinal $(n=3)$ [88, 91, 92], and crosssectional $(n=4)$ [37, 40, 93, 94]. Indicators of motor development were measured objectively (e.g., visual-motor abilities measured using the Wide-Range Assessment of Visual Motor Ability) or assessed subjectively by parentreport (e.g., age at first sitting; see Table 2 for summary of measures). The quality of evidence was "very low" across study designs (Table 2).

Among the three longitudinal studies, sedentary behaviour was assessed from age 3.9 months to 2.4 years as screen-based (i.e., TV time) or other sedentary behaviours (i.e., time in a baby carrier/sling, car seat, high chair/other chair, playpen, or stroller). Motor development indicators were assessed after 1.3 to 3 years of follow-up. For screenbased sedentary behaviours, TV time was not prospectively associated with age at first sitting, crawling, or walking [91], visual-motor abilities [88], or object control [92], but was unfavourably associated with locomotion skills [92].

Regarding other sedentary behaviours, infants' time in a baby carrier/sling, stroller, high chair or other chair, or playpen was not associated with age at first sitting, crawling, or walking [91] (Additional file 2: Table S2). Greater time in a car seat at age $\sim 9$ months was associated with earlier (i.e., favourable) age at first sitting and age at first crawling, but was not associated with age at first walking; time spent in a car seat at ages $\sim 4$ months and 1.7 years was not associated with age at first sitting, crawling, or walking [91].

In the 4 cross-sectional studies, sedentary behaviour was assessed as accelerometer-derived sedentary time, screen-based (i.e., TV time), or other sedentary behaviours (i.e., time in the supine position). The relationships between accelerometer-derived sedentary time and motor development were examined in two of the crosssectional studies. Total sedentary time was not associated with motor skills at age $\sim 2$ years [40] or $\sim 3$ to 4 years [37], or with object control skills at age $\sim 3$ to 4 years [37], but \% sedentary time was unfavourably associated with locomotor skills at age $\sim 3$ to 4 years [37]. The number of 30-min bouts of sedentary behaviour was not associated with motor skills [40].

For screen-based sedentary behaviours, TV time was unfavourably associated with motor skill development; children with delayed motor skill development spent more time watching TV compared to children with typical motor skill development, and children who were frequently exposed to TV $(>0 \mathrm{~h} /$ day for children $<2$ years and $>2 \mathrm{~h}$ /day for children $\geq 2$ years) were more likely to have delayed motor skill development than those who were infrequently exposed [94].

For other sedentary behaviours, time in the supine position before 6 months of age was not associated with gross motor performance, but time in the supine position after age 6 months was unfavourably associated with gross motor performance [93].

\section{Psychosocial health}

The relationships between sedentary behaviour and psychosocial health in toddlers and preschoolers were examined in 15 studies (no studies in infants; see Table 3 and Additional file 2: Table S3) [34, 90, 92, 95-106]. Study designs were: randomized controlled trial $(n=1)$ [34], longitudinal $(n=9)$ [90, 92, 95-97, 99, 100, 102, $103]$, and cross-sectional design or additionally reported cross-sectional findings $(n=7)$ [98, 100, 101, 103-106]. Indicators of psychosocial health (e.g., aggression, 
symptoms of anxiety and depression) were assessed subjectively by parent-, teacher-, or self-report using questionnaires (see Table 3 for summary of measures). The quality of evidence ranged from "very low" to "moderate" across study designs (Table 3).

In the randomized controlled trial of an intervention to reduce screen time, preschoolers' screen time was significantly lower in the intervention versus control group at 2, 6, and 9 months post-intervention [34]. Aggressive and delinquent behaviours were not significantly different between the intervention and control groups at baseline, but were significantly lower in the intervention versus control group at 9-months post-intervention [34] (Additional file 2: Table S3).

Among the nine longitudinal studies, screen-based sedentary behaviour (i.e., time e-gaming or on a computer, or TV time) was assessed from age $\sim 1.5$ to 5 years. Psychosocial health indicators were assessed after $\sim 1$ to 9.5 years of follow-up.

Time spent e-gaming or on a computer (on weekdays or weekend days) at age 4.3 years was not associated with being at risk for the following at age 6.3 years: peer problems, self-esteem problems, social well-being problems, social functioning problems, or family functioning problems [96]. Time spent e-gaming or on a computer on weekdays (but not weekend days) at age 4.3 years was unfavourably associated with being at risk for emotional problems at age 6.3 years in girls but not boys [96] (Additional file 2: Table S3).

The relationships between TV time among toddlers/ preschoolers and psychosocial health indicators at follow-up were examined in nine longitudinal studies; unfavourable associations were reported in $2 / 9$ studies [95, 103], null associations in 1/9 studies [100], mixed unfavourable and null associations in 5/9 studies [90, 92, 96, 97, 99], and mixed null and favourable associations in 1/9 studies [102] (Additional file 2: Table S3). Specifically, TV time was prospectively unfavourably associated with the following psychosocial health indicators: victimization [90, 95], victimization by classmates [92], being a victim of bullying [97], being a bully [103], externalizing problems [99], and being at risk for family functioning problems [96] (Additional file 2: Table S3). Null associations were reported between TV time and emotional symptoms [100]; conduct problems [100]; peerproblems [100]; prosocial behaviour [92, 100]; externalizing problems [99, 102]; anxiety or depressive symptoms [92, 102]; physical aggression [100] or aggressive behaviour [102]; being a bully, being a victim of bullying, or being a bully-victim [97]; being at risk for emotional problems, peer problems, self-esteem problems, emotional well-being problems, or social functioning problems [96]; and co-operation, self-control, assertion, responsibility, or total social skills [102]. TV time at age $\sim 2.5$ years was favourably associated with emotional reactivity scores after $\sim 3$ years of follow-up [102].

In the 7 cross-sectional studies, sedentary behaviour was assessed as accelerometer-derived total sedentary time or screen-based (i.e., TV time) sedentary behaviour. Total sedentary time (accelerometer-derived) was not cross-sectionally associated with preschoolers' psychosocial health indicators (soothability, sociability, or emotionality) [104].

The relationships between TV time and psychosocial health indicators in toddlers and preschoolers were examined in six cross-sectional studies; unfavourable associations were reported in $2 / 6$ studies [101, 103], null associations in $2 / 6$ studies $[100,106]$, mixed unfavourable and null associations in $1 / 6$ studies [105], and mixed unfavourable and favourable associations in $1 / 6$ studies [98]. Specifically, TV time was unfavourably associated with aggression [101], bullying [103], total externalizing behaviour problems [105], and total behaviour problems [105]. Null associations were reported between TV time and emotional symptoms, conduct problems, peer problems, and prosocial behaviour [100], aggression toward a sibling [106], and internalizing behaviour problems [105]. TV time was favourably associated with social-emotional competence in one study [98].

\section{Cognitive development}

The relationships between sedentary behaviour and cognitive development were examined in 25 studies (see Table 4 and Additional file 2: Table S4) $[88,90,92,94$, $100,102,104,107-124]$. Study designs were: longitudinal $(n=11)$ [88, 90, 92, 100, 102, 112, 113, 119-122], case-control $(n=1)$ [116], and cross-sectional design or additionally reported cross-sectional findings $(n=16)$ $[90,94,100,104,107-111,114,115,117,118,121,123$, 124]. Indicators of cognitive development were measured objectively (e.g., working memory capacity measured using the Memory for Digit Span test) or assessed subjectively by parent-report interview or questionnaire (e.g., receptive vocabulary; see Table 4 for summary of measures). The quality of evidence was "very low" across study designs (Table 4).

Among the 11 longitudinal studies, sedentary behaviour was assessed from age $\sim 6$ months to 5 years as screen-based (i.e., electronic media exposure and TV time) or other sedentary behaviours (i.e., frequency of parents reading). Cognitive development indicators were assessed after $\sim 8$ months to 8 years of follow-up.

For screen-based sedentary behaviours, electronic media exposure at age $\sim 6$ months was unfavourably associated with the following at age 14 months: cognitive development, language development, and auditory comprehension [112]. The relationships between TV 
time and cognitive development indicators in toddlers and preschoolers were examined in 10 longitudinal studies; unfavourable associations were reported in $5 / 10$ studies [90, 92, 100, 120,121], null associations in 4/10 studies [88, 102, 113, 122], and mixed unfavourable, null, and favourable associations in $1 / 10$ studies [119]. Specifically, TV time was prospectively unfavourably associated with the following cognitive development indicators: rate of change in language development [121], receptive vocabulary and number knowledge [92], classroom engagement [90, 92], mathematical achievement [90], attentional problems [120], and hyperactivityinattention [100] (Additional file 2: Table S4).

Regarding other sedentary behaviours, the frequency of parents reading to their child from ages $\sim 8$ months to 4 years was favourably associated with both language development at age 4 years and the rate of change in language development between ages 5 to 7 years [121] (Additional file 2: Table S4).

In the case-control study, toddlers with language delay (cases) had significantly greater TV time than those with normal language development (controls) [116]. Compared with toddlers who viewed $\leq 2 \mathrm{~h} /$ day TV time, those with $>2 \mathrm{~h}$ /day TV time had increased odds of language delay [116].

In the 16 cross-sectional studies, sedentary behaviour was assessed as accelerometer-derived sedentary time, screen-based (i.e., computer use, mobile phone use, time playing inactive video games, TV time, total media exposure, and total screen time), or other sedentary behaviours (i.e., reading or storytelling with parents). Only one crosssectional study examined the association between accelerometer-derived total sedentary time and cognitive development indicators; total sedentary time was not associated with attention span in preschoolers [104].

For screen-based sedentary behaviours, computer use was not associated with the prevalence of speech disorders, but mobile phone use (any versus none) was unfavourably associated with speech disorders in toddlers and preschoolers [109]. Time playing inactive video games was not associated with hyperactivity or attention problems in preschoolers [107]. Total screen time was unfavourably associated with communication development in toddlers [111], and total media exposure was unfavourably associated with receptive language development and expressive language development in infants and toddlers aged $\sim 6$ months to 1.3 years, but not with total language development in toddlers aged $\sim 1.4$ to 2.3 years [124].

The relationships between TV time and cognitive development in toddlers and preschoolers were examined in nine cross-sectional studies; unfavourable associations were reported in $3 / 9$ studies [94, 108, 123], null associations in $5 / 9$ studies [90, 100, 114, 115, 121], and mixed unfavourable and null associations in 1/9 studies [118] (see Additional file 2: Table S4 for statistics). Specifically, TV time was unfavourably associated with language development or capacity in $2 / 5$ studies $[94,108]$ (Additional file 2: Table S4). TV time was unfavourably associated with delayed executive function [123] and cognitive development [94], but was not associated with cognitive ability [90] (Additional file 2: Table S4). TV time was not associated with hyperactivity-inattention in toddlers [100], and was unfavourably associated with teacher-reported, but not parent-reported, attentiondeficit/hyperactivity disorder (ADHD) symptoms in preschoolers [118] (Additional file 2: Table S4).

Regarding other sedentary behaviours, the relationships between reading with parents and cognitive development indicators in infants, toddlers, and preschoolers were examined in three cross-sectional studies [110, 117, 124], two of which analyzed the same dataset in different ways [117, 124]; reading with parents was favourably associated with language development percentile in both infants and toddlers [117], but was not associated with absolute language development in toddlers (not analyzed in infants) [124]. Reading with parents was favourably associated with absolute receptive language development, but not expressive language development, in infants [124]. In the third study, reading with parents was not associated with executive function in preschoolers [110]. Storytelling with parents was favourably associated with language development percentile in infants [117]. In toddlers, storytelling was favourably associated with absolute language development [124], but not language development percentile [117]. Storytelling with parents was favourably associated with absolute receptive language development, but not expressive language development, in infants [124] (Additional file 2: Table S4).

\section{Important (secondary) health indicators Bone and skeletal health}

The relationship between sedentary behaviour and bone and skeletal health in preschoolers was examined in one cross-sectional study (see Table 5 and Additional file 2: Table S5) [125]. The quality of evidence was rated as "very low". As summarized in Table 5, parent-reported screen time and accelerometer-derived total sedentary time were not associated with bone stiffness index in preschool children [125]. No other indices of bone and skeletal health were examined.

\section{Cardiometabolic health}

The relationship between sedentary behaviour and cardiometabolic health in preschoolers was examined in one cross-sectional study (see Table 6 and Additional file 2: Table S6) [126]. The quality of evidence was rated as "very low". Watching TV for $\geq 2 \mathrm{~h}$ /day was 
not associated with high blood pressure in preschool children [126]. No other cardiometabolic biomarkers were examined.

\section{Fitness}

The relationship between sedentary behaviour and fitness in toddlers and preschoolers was examined in two longitudinal studies (no studies in infants; see Table 7 and Additional file 2: Table S7) [89, 90]. The quality of evidence was rated as "very low".

As summarized in Table 7, greater TV time at age $\sim 2.4$ years was unfavourably associated with standing long-jump performance at age $\sim 8.2$ years [89] and physical fitness level (assessed as "relative to other children" via parent-report) in Grade 4 (age $\sim 10$ years) [90]. A greater increase in $\mathrm{TV}$ time between age $\sim 2.4$ and $\sim 4.4$ years was unfavourably associated with standing long-jump performance at age 8.2 years [89] and physical fitness level in Grade 4 [90].

\section{Risks/harm}

No studies examined harms associated with sedentary behaviour.

\section{Discussion}

The objective of this study was to perform a systematic review that examined the relationships between sedentary behaviours and health indicators in children 0 to 4 years, and to determine what doses of sedentary behaviours (i.e., duration, patterns [frequency, interruptions], and type) were associated with health indicators. The main findings are the following: 1) associations between objectively measured total sedentary time and health indicators (adiposity and motor development) were predominantly null; 2) associations between screen-based sedentary behaviours and health indicators (adiposity, motor or cognitive development, and psychosocial health) were largely unfavourable or null; 3) associations between reading or storytelling and cognitive development were favourable or null; and 4) associations between time spent seated (e.g., in baby seats, car seats, high chairs or strollers) or in the supine position and health indicators (adiposity, motor development) were primarily unfavourable or null. Few studies examined indicators of bone and skeletal health, cardiometabolic health, or fitness, and no studies reported on risks or harms (e.g., torticollis, injuries) associated with sedentary behaviours. These findings suggest that, in the early years, total sedentary time may have a negligible impact on health, but the way that time is spent is important, with screen-based and seated/supine sedentary behaviours likely to have unfavourable or null health effects (unlikely to have favourable effects), and interactive nonscreen-based activities such as reading and storytelling likely to have favourable health effects. A summary of the findings is presented in Table 8.

The finding that there are no associations between objectively measured total sedentary time and health indicators in the early years ( 0 to 4 years) is in contrast to the relationships in older age groups, in particular adults $[4,127]$. While this suggests that in the early years a certain amount of sedentary behaviour may be innocuous and perhaps even necessary for healthy growth and development, these findings should be interpreted with caution. First, objectively measured total sedentary time was examined only in cross-sectional studies, and a plausible explanation for the perceived lack of association between total sedentary time and health indicators is that there had simply been insufficient time for those effects to manifest, rather than there being no effect. This hypothesis is supported by comparison of findings from longitudinal and cross-sectional studies for subsets of total sedentary behaviour. For instance, 9/10 (90\%) longitudinal studies reported at least one unfavourable association between TV time and adiposity indicators, compared to only $11 / 22(50 \%)$ cross-sectional studies. However, total sedentary time was examined only in relation to adiposity and motor development (and in one study each for indicators of psychosocial health, cognitive development, and bone and skeletal health); it remains possible that total sedentary time is associated with other health indicators, particularly those likely to be acutely affected in the early years, such as cognitive development. More well-designed studies with objective measures of sedentary behaviour are needed.

Second, in the present review, studies that utilized accelerometry measures applied a range of sampling intervals (epochs) and cut-points. Given that these measurement parameters influence the amount of sedentary behaviour captured [128, 129], individual studies may have under- or overestimated the total amount of sedentary time and may therefore have resulted in an underestimation or overestimation of true effects. However, Byun et al. applied three different accelerometry cutpoints in two cross-sectional datasets to test whether this would influence the findings, and found no association between total sedentary time and BMI $\mathrm{z}$-score, regardless of the cut-points used [38]. Nonetheless, the most appropriate way to objectively measure sedentary behaviour in the early years is still unknown and remains an important area for future work.

Lastly, total sedentary time was not objectively assessed in any studies in the infant age group; however, such measures may not be meaningful in nonambulatory infants. Although the associations between total sedentary time and health indicators were primarily null, the present data do not allow for recommendations 
regarding "appropriate" amounts or patterning (e.g., breaks) of total sedentary time.

Regarding screen-based sedentary behaviours, the present findings support and extend those of the earlier systematic review [2]; overall, screen time (namely TV time) was unfavourably associated with a range of health indicators. Notably, TV time was the predominant measure of screen-based behaviour, followed by total screen time, with only eight studies reporting relationships between computer use and any health indicator; two studies for each of DVDs/videos, electronic/total media exposure, and inactive video games; and one study for mobile phone and internet use. Findings for these other screen exposures were mixed (unfavourable or null), and suggest no benefits and some potential for harm. Although it seems intuitive that different types of screens may exert different effects (e.g., interacting on video-chat versus passive screen use), research on children's use of such technologies lags behind their adoption [130]; this is a substantial research gap. Importantly, screen-based behaviours are used as a proxy for sedentary behaviour; however, it is uncertain whether children in this age group are actually sedentary while using screens, and there may be screen-related health effects that are independent of the "lack of movement" [131, 132]. Notwithstanding these limitations, the present findings indicate that less screen-based sedentary behaviour is better for optimal health in the early years of life.

Other sedentary behaviour exposures were less frequently examined, and findings were mixed. In general, reading $[110,117,121,124]$ and storytelling $[117,124]$ were favourably associated with cognitive development, while various types of time spent seated (e.g., in a car seat, high chair, or stroller) had mixed unfavourable and null associations with indicators of adiposity and motor development [45, 81, 82, 91]. An age-dependent effect was observed in the only study that assessed time in the supine position; time spent supine before 6 months of age was not associated with gross motor performance, but greater time in the supine position after age 6 months was associated with worse gross motor performance [93]. Overall, there was a paucity of data regarding the relationships between other types of sedentary behaviours and health indicators. Research shows that children are spending $\sim 7 \mathrm{~h}$ of the day in sedentary pursuits [15], and $\sim 2 \mathrm{~h}$ of these are occupied by screen time [15]; this leaves an additional $5 \mathrm{~h}$ that are unaccounted for. Other types of sedentary behaviours are thus highly understudied, and this is an important research gap.

Most studies examined the duration of sedentary behaviours in relation to health indicators, with only three studies specifically examining the impact of patterns of behaviour (i.e., breaks, frequency). Specifically, there was no association between accelerometer-derived sedentary time in 30-min bouts and indicators of adiposity and motor development [40], or between the frequency of playing computer games and adiposity indicators [82], but there were favourable associations between the frequency of parents reading or storytelling and child cognitive development [121]. These findings are consistent with those of studies that examined sedentary behaviour duration; however, it remains difficult to draw conclusions regarding patterns of sedentary behaviour for optimal health in the early years.

\section{Strengths, limitations, and future directions}

Strengths of this review include the use of a comprehensive search strategy that was developed and peerreviewed by librarians with expertise in systematic reviews, as well as inclusion of all study designs and a broad range of health indicators that represent various dimensions of health. Rigorous methodological standards were used in this review, including application of the GRADE framework to guide the review process and assess the quality of the evidence [27]. To our knowledge, this systematic review is the first to synthesize the evidence regarding the relationships between objectively and subjectively measured sedentary behaviour across the most comprehensive range of health indicators in children in the early years of life.

In terms of limitations, sample size restrictions were imposed for feasibility reasons and to maximize generalizability, but it is possible that studies with smaller sample sizes might have provided additional insight. Further, because of heterogeneity in the measurement of sedentary behaviour and health indicators, meta-analyses were not possible and all studies were weighted equally in the narrative synthesis. The direction of associations (i.e., unfavourable, null, favourable) was based on statistical significance; clinical significance was not considered.

Although an abundance of evidence was synthesized in this review, several limitations of this area of research were identified that remain to be addressed. As mentioned, data were limited regarding the relationships between sedentary behaviour and four relevant health indicators (two or fewer studies for each of bone and skeletal health, cardiometabolic health, fitness, and risks/ harms); TV time was the primary sedentary exposure, with few studies examining "other" types of screens (e.g., tablets, mobile phones) or sedentary behaviours (e.g., reading, puzzles); and objective measures of total sedentary time were employed only in cross-sectional studies. Although adiposity was the most commonly measured health indicator (60 studies), direct measures of adiposity were used in only two studies $[78,82]$ while the remainder used surrogate measures such as BMI. Only 
one randomized controlled study was included in the present review, and the quality of the evidence ranged from "very low" to "moderate" across the study designs and health indicators. There is a need for high-quality studies with strong designs to better establish the magnitude of effects and the nature of dose-response gradients (if applicable), to assess cause-and-effect relationships, and to examine potential subgroup differences (e.g., based on age, sex, or socio-economic status). When RCTs are not possible because of the inherent challenges of research in this age group, quasi-experimental or longitudinal designs that use validated sedentary behaviour measures and outcome measures that are sensitive enough to detect changes are recommended.

Across the health indicators, the most common reason for downgrading the quality of evidence was the serious risk of bias associated with sedentary behaviour measures with no known psychometric properties. Consequently, development and use of reliable and valid subjective measures of sedentary behaviour are needed. Defining and measuring sedentary behaviour in young children, particularly in nonambulatory infants, remains a challenge. For instance, infants in the supine position may be vigorously moving arms and legs, and thus being "active", but existing questionnaire-based measures do not capture this. Future research using inclinometers, which can more accurately capture postures [133], as well as limb-worn devices, will help to address the challenges associated with quantifying sedentary behaviours in the early years. Finally, the question of whether different types of sedentary behaviour "content" (e.g., educational versus recreational TV programming) exert different health effects was beyond the scope of this review, and remains an important area for future work.

\section{Conclusions}

This systematic review synthesized findings from 96 studies with 200,000 participants in 33 countries around the world; the quality of the evidence ranged from "very low" to "moderate". In summary, the findings demonstrate that in the early years ( 0 to 4 years), total sedentary time may have a negligible impact on health, but the quality of that time is important, with screen-based and seated/supine sedentary behaviours likely to have no benefit and a potential for harm, and interactive non-screen-based activities such as reading with caregivers having favourable health effects. These findings continue to support the importance of minimizing screen time for disease prevention and health promotion in the early years [2, 9], and also highlight the potential benefits of interactive non-screen-based sedentary behaviours such as reading and storytelling. There is a need for additional research using valid and reliable measures and high-quality study designs, to more definitively establish the relationships between sedentary behaviours and health indicators, and to provide insight into the appropriate dose (durations, patterns, type) of sedentary behaviour for optimal health in the early years.

\section{Additional files}

Additional file 1: Search strategies. (PDF $58 \mathrm{~kb}$ )

Additional file 2: Supplementary Tables S1-S7. (PDF 1166 kb)

\section{Abbreviations}

ADHD: Attention-deficit/hyperactivity disorder; BMl: Body mass index GRADE: Grading of recommendations, assessment, development and evaluation; METS: Metabolic equivalent; PICOS: Population, intervention, comparison, outcomes and study designs framework; PRISMA: Preferred reporting items for systematic reviews and meta-analyses; RCT: Randomized controlled trial; SB: Sedentary behaviour; TV: Television

\section{Acknowledgments}

The authors wish to acknowledge the work of Linda Slater for peer review of the search strategies, Alejandra Jaramillo Garcia and Véronique Dorais for methodological consultation, and Nick Barrowman and Katie Gunnell for statistical consultation.

\section{Funding}

This study has been made possible through funding from the Canadian Institutes of Health Research (CIHR; Grant KRS-144044), Canadian Society for Exercise Physiology, Healthy Active Living and Obesity Research Group at the Children's Hospital of Eastern Ontario Research Institute, and the Public Health Agency of Canada. Publication charges for this article have been funded by CIHR Grant KRS-144044. Valerie Carson is supported by a Canadian Institutes of Health Research New Investigator Salary Award. Guy Faulkner is supported by a Chair Award in Applied Public Health funded by the Public Health Agency of Canada in partnership with the Canadian Institutes of Health Research.

\section{Availability of data and materials}

Not applicable.

\section{About this supplement}

This article has been published as part of BMC Public Health Volume 17 Supplement 5, 2017: 24-Hour Movement Guidelines for the Early Years: An Integration of Physical Activity, Sedentary Behaviour, and Sleep. The full contents of the supplement are available online at https://bmcpublichealth.biomedcentral.com/articles/supplements/volume-17-supplement-5.

\section{Authors' contributions}

VJP, CEG, and MST were responsible for the initiation, conceptualization, and design of the systematic review. VJP, CEG, XJ, and SA were responsible for data collection and extraction and for risk of bias assessment. VJP and CEG were responsible for the GRADE analysis and interpretation of data. VJP was the primary author of the manuscript. All authors (VJP, CEG, XJ, SA, VC, GF, GSG, JJR, MS, and MST) were responsible for revising the manuscript critically for important intellectual content. All authors read and approved the final manuscript.

Ethics approval and consent to participate

Not applicable.

\section{Consent for publication}

Not applicable.

Competing interests

The authors declare that they have no competing interests.

\section{Publisher's Note}

Springer Nature remains neutral with regard to jurisdictional claims in published maps and institutional affiliations. 


\section{Author details}

'Healthy Active Living and Obesity Research Group, Rl \#1, Children's Hospital of Eastern Ontario Research Institute, 401 Smyth Road, Ottawa, ON K1H 8L1, Canada. ${ }^{2}$ University of Strathclyde, School of Psychological Science and Health, G1 1QE, Glasgow, Scotland, UK. ${ }^{3}$ Faculty of Physical Education and Recreation, University of Alberta, Edmonton, AB T6G 2H9, Canada. ${ }^{4}$ School of Kinesiology, University of British Columbia, Vancouver, BC V6T 1Z3, Canada. 5Library and Media Services, Children's Hospital of Eastern Ontario, Ottawa, ON K1H 8L1, Canada.

\section{Published: 20 November 2017}

\section{References}

1. Sedentary Behaviour Research Network. Letter to the editor: standardized use of the terms "sedentary" and "sedentary behaviours". Appl Physiol Nutr Metab. 2012;37:540-2. http://dx.doi.org/10.1139/h2012-024. Accessed 25 Nov 2016.

2. LeBlanc AG, Spence JC, Carson V, Connor Gorber S, Dillman C, Janssen I, et al. Systematic review of sedentary behaviour and health indicators in the early years (aged 0-4 years). Appl Physiol Nutr Metab. 2012;37:753-72. PM: 22765839

3. Tremblay MS, LeBlanc AG, Janssen I, Kho ME, Hicks A, Murumets K, et al. Canadian sedentary behaviour guidelines for children and youth. Appl Physiol Nutr Metab. 2011;36:59-64. PM:21326378.

4. Thorp AA, Owen N, Neuhaus M, Dunstan DW. Sedentary behaviors and subsequent health outcomes in adults: a systematic review of longitudinal studies, 1996-2011. Am J Prev Med. 2011;41:207-15. PM: 21767729.

5. Biswas A, Oh PI, Faulkner GE, Bajaj RR, Silver MA, Mitchell MS, et al. Sedentary time and its association with risk for disease incidence, mortality, and hospitalization in adults: a systematic review and meta-analysis. Ann Intern Med. 2015;162:123-32. PM:25599350.

6. Reilly JJ, Jackson DM, Montgomery C, Kelly LA, Slater C, Grant S, et al. Total energy expenditure and physical activity in young Scottish children: mixed longitudinal study. Lancet. 2004;363:211-2. http://www.sciencedirect.com/ science/article/pii/S0140673603153317.

7. Janz KF, Burns TL, Levy SM. Tracking of activity and sedentary behaviors in childhood: the lowa bone development study. Am J Prev Med. 2005;29:171-8. http://www.sciencedirect.com/science/article/pii/S0749379705002023.

8. Biddle SJ, Pearson N, Ross GM, Braithwaite R. Tracking of sedentary behaviours of young people: a systematic review. Prev Med. 2010;51:345-51. PM:20682330

9. Tremblay MS, LeBlanc AG, Carson V, Choquette L, Connor Gorber S, Dillman C, et al. Canadian sedentary behaviour guidelines for the early years (aged 0-4 years). Appl Physiol Nutr Metab. 2012;37:370-91. PM:22448609.

10. Australian Government Department of Health. Move and play every day: national physical activity recommendations for children 0-5 years. 2014. http://www. health.gov.au/internet/main/publishing.nsf/Content/npra-0-5yrs-brochure.

11. American Academy of Pediatrics, Council on Communications and Media. Children, adolescents, and the media. Pediatrics. 2013;132:958-61. 10.1542/peds. 2013-2656. http://pediatrics.aappublications.org/content/132/5/958.abstract.

12. Department of Health PAHIaP. Start active, stay active: a report on physical activity for health from the four home countries' Chief Medical Officers. 2011. https://www.gov.uk/government/uploads/system/uploads/ attachment_data/file/216370/dh_128210.pdf.

13. Carson V, Tremblay MS, Spence JC, Timmons BW, Janssen I. The Canadian sedentary behaviour guidelines for the early years (zero to four years of age) and screen time among children from Kingston, Ontario. Paediatr Child Health. 2013:18:25-8. PM:24381488.

14. Zimmerman FJ, Christakis DA, Meltzoff AN. Television and DVD/video viewing in children younger than 2 years. Arch Pediatr Adolesc Med. 2007;161:473-9. PM:17485624.

15. Garriguet D, Carson V, Colley RC, Janssen I, Timmons BW, Tremblay MS. Physical activity and sedentary behaviour of Canadian children aged 3 to 5 . Health Rep. 2016;27:14-23. PM:27655168.

16. Hnatiuk JA, Salmon J, Hinkley T, Okely AD, Trost S. A review of preschool children's physical activity and sedentary time using objective measures. Am J Prev Med. 2014:47:487-97. PM:25084681.

17. Inchley J, Currie D, Young T, Samdal O, Torsheim T, Augustson L, et al., editors. Growing up unequal: gender and socioeconomic differences in young people's health and well-being. Health behaviour in school-aged children (HBSC) study: international report from the 2013/2014 survey. Copenhagen: World Health Organization; 2016.

18. Carson V, Kuzik N, Hunter S, Wiebe SA, Spence JC, Friedman A, et al. Systematic review of sedentary behavior and cognitive development in early childhood. Prev Med. 2015;78:115-22. PM:26212631.

19. Carson V, Hunter S, Kuzik N, Gray CE, Poitras VJ, Chaput JP, et al. Systematic review of sedentary behaviour and health indicators in school-aged children and youth: an update. Appl Physiol Nutr Metab. 2016;41:S240-65. PM:27306432.

20. Carson V, Wong SL, Winkler E, Healy GN, Colley RC, Tremblay MS. Patterns of sedentary time and cardiometabolic risk among Canadian adults. Prev Med. 2014;65:23-7.

21. Hinkley T, Teychenne M, Downing KL, Ball K, Salmon J, Hesketh KD. Early childhood physical activity, sedentary behaviors and psychosocial wellbeing: a systematic review. Prev Med. 2014;62:182-92. PM:24534461.

22. Moher D, Liberati A, Tetzlaff J, Altman DG. The PRISMA group. Preferred reporting items for systematic reviews and meta-analyses: the PRISMA statement. J Clin Epidemiol. 2009;62:1006-12. PM:19631508.

23. Schardt C, Adams MB, Owens T, Keitz S, Fontelo P. Utilization of the PICO framework to improve searching PubMed for clinical questions. BMC Med Inform Decis Mak. 2007;7:16. PM:17573961.

24. LeBlanc AG, Chaput JP, MCFarlane A, Colley RC, Thivel D, Biddle SJH, et al. Active video games and health indicators in children and youth: a systematic review. PLoS One. 2013;8:e65351. PM:23799008.

25. Poitras VJ, Gray CE, Borghese MM, Carson V, Chaput JP, Katzmarzyk PT. Systematic review of the relationships between objectively measured physical activity and health indicators in school-aged children and youth. Appl Physiol Nutr Metab. 2016;41:S197-239. PM:27306431.

26. Higgins JP, Altman DG, Gotzsche PC, Juni P, Moher D, Oxman AD, et al. The Cochrane Collaboration's tool for assessing risk of bias in randomised trials. BMJ. 2011;343:d5928. PM:22008217.

27. Guyatt G, Oxman AD, Akl EA, Kunz R, Vist G, Brozek J, et al. GRADE guidelines: 1. Introduction - GRADE evidence profiles and summary of findings tables. J Clin Epidemiol. 2011;64:383-94. PM:21195583.

28. Balshem H, Helfand M, Schunemann HJ, Oxman AD, Kunz R, Brozek J, et al. GRADE quidelines: 3. Rating the quality of evidence. J Clin Epidemiol. 2011; 64:401-6. PM:21208779.

29. Guyatt GH, Oxman AD, Sultan S, Glasziou P, Akl EA, Alonso-Coello P, et al. GRADE guidelines: 9. Rating up the quality of evidence. J Clin Epidemiol. 2011;64:1311-6. PM:21802902.

30. Timmons BW, LeBlanc AG, Carson V, Connor Gorber S, Dillman C, Janssen I, et al. Systematic review of physical activity and health in the early years (aged 0-4 years). Appl Physiol Nutr Metab. 2012;37:773-92. PM:22765840

31. Proctor MH, Moore LL, Gao D, Cupples LA, Bradlee ML, Hood MY, et al. Television viewing and change in body fat from preschool to early adolescence: the Framingham Children's study. Int J Obes Relat Metab Disord. 2003;27:827-33. 12821969.

32. Chiasson M, Scheinmann R, Hartel D, McLeod N, Sekhobo J, Edmunds LS, et al. Predictors of obesity in a cohort of children enrolled in WIC as infants and retained to 3 years of age. J Community Health. 2016;41: $127-33$.

33. Olafsdottir S, Berg C, Eiben G, Lanfer A, Reisch L, Ahrens W, et al. Young children's screen activities, sweet drink consumption and anthropometry: results from a prospective European study. Eur J Clin Nutr. 2014;68:223-8. PM:24253759.

34. Yilmaz G, Demirli CN, Karacan CD. An intervention to preschool children for reducing screen time: a randomized controlled trial. Child Care Health Dev. 2015;41:443-9. PM:24571538.

35. Koleilat M, Harrison GG, Whaley S, McGregor S, Jenks E, Afifi A. Preschool enrollment is associated with lower odds of childhood obesity among WIC participants in LA County. Matern Child Health J. 2012;16:706-12. PM: 21431308.

36. Kain J, Andrade M. Characteristics of the diet and patterns of physical activity in obese Chilean preschoolers. Nutr Res. 1999;19:203-15.

37. Williams HG, Pfeiffer KA, O'Neill JR, Dowda M, Mclver KL, Brown WH, et al. Motor skill performance and physical activity in preschool children. Obesity (Silver Spring). 2008;16:1421-6. PM:18388895.

38. Byun W, Liu J, Pate RR. Association between objectively measured sedentary behavior and body mass index in preschool children. Int J Obes. 2013;37: 961-5. PM:23318716. 
39. Byun W, Dowda M, Pate RR. Correlates of objectively measured sedentary behavior in US preschool children. Pediatrics. 2011;128:937-45. PM: 22007010.

40. Johansson E, Hagstromer M, Svensson V, Anna EK, Forssen M, Nero H, et al. Objectively measured physical activity in two-year-old children - levels, patterns and correlates. Int J Behav Nutr Phys Act. 2015;12:ArtID 3.

41. Anderson SE, Whitaker RC. Household routines and obesity in US preschoolaged children. Pediatrics. 2010;125:420-8. PM:20142280.

42. DuRant RH, Baranowski T, Johnson M, Thompson WO. The relationship among television watching, physical activity, and body composition of young children. Pediatrics. 1994;94:449-55. PM:7936851.

43. Burdette HL, Whitaker RC. A national study of neighborhood safety, outdoor play, television viewing, and obesity in preschool children. Pediatrics. 2005; 116:657-62. PM:16140705.

44. Lioret $S$, Maire B, Volatier $\mathrm{L}$, Charles MA. Child overweight in France and its relationship with physical activity, sedentary behaviour and socioeconomic status. Eur J Clin Nutr. 2007:61:509-16. PM:16988644.

45. Sijtsma A, Sauer PJ, Stolk RP, Corpeleijn E. Infant movement opportunities are related to early growth - GECKO Drenthe cohort. Early Hum Dev. 2013; 89:457-61. PM:23631950

46. Sijtsma A, Koller M, Sauer PJ, Corpeleijn E. Television, sleep, outdoor play and BMI in young children: the GECKO Drenthe cohort. Eur J Pediatr. 2015; 174:631-9. PM:25367053.

47. Wijtzes Al, Kooijman MN, Kiefte-de Jong JC, de Vries SI, Henrichs J, Jansen W, et al. Correlates of physical activity in 2-year-old toddlers: the generation R study. J Pediatr. 2013;163:791-9. PM:23523279.

48. Manios Y, Kourlaba G, Kondaki K, Grammatikaki E, Anastasiadou A, Roma-Giannikou E. Obesity and television watching in preschoolers in Greece: the GENESIS study. Obesity (Silver Spring). 2009;17:2047-53. PM: 19282823.

49. Kourlaba G, Kondaki K, Liarigkovinos T, Manois Y. Factors associated with television viewing time in toddlers and preschoolers in Greece: the GENESIS study. J Public Health (Oxf). 2009;31:222-30. PM:19224946.

50. van Stralen MM, te Velde SJ, van Nassau F, Brug J, Grammatikaki E, Maes L, et al. Weight status of European preschool children and associations with family demographics and energy balance-related behaviours: a pooled analysis of six European studies. [review]. Obes Rev. 2012;13 Suppl 1:29-41. PM:22309063.

51. Wen LM, Baur LA, Rissel C, Xu H, Simpson JM. Correlates of body mass index and overweight and obesity of children aged 2 years: findings from the healthy beginnings trial. Obesity (Silver Spring). 2014;22:1723-30. PM:24415528.

52. Turer CB, Stroo M, Brouwer RJ, Krause KM, Lovelady CA, Bastian LA, et al. Do high-risk preschoolers or overweight mothers meet AAP-recommended behavioral goals for reducing obesity? Acad Pediatr. 2013;13:243-50. PM:23491583.

53. Dolinsky DH, Brouwer RJ, Evenson KR, Ostbye T, Evenson KR, Siega-Riz AM. Correlates of sedentary time and physical activity among preschool-aged children. Prev Chronic Dis. 2011:8:A131. PM:22005624

54. Fuller-Tyszkiewicz M, Skouteris $H$, Hardy LL, Halse C. The associations between TV viewing, food intake, and BMI. A prospective analysis of data from the longitudinal study of Australian children. Appetite. 2012;59:945-8. PM:23000277.

55. Brown JE, Broom DH, Nicholson JM, Bittman M. Do working mothers raise couch potato kids? Maternal employment and children's lifestyle behaviours and weight in early childhood. Soc Sci Med. 2010;70:1816-24. PM:20299142.

56. Dubois L, Farmer A, Girard M, Peterson K. Social factors and television use during meals and snacks is associated with higher BMl among pre-school children. Public Health Nutr. 2008;11:1267-79. PM:18547454.

57. Dennison BA, Erb TA, Jenkins PL. Television viewing and television in bedroom associated with overweight risk among low-income preschool children. Pediatrics. 2002;109:1028-35. PM:12042539.

58. Asplund KM, Kair LR, Arain YH, Cervantes M, Oreskovic NM, Zuckerman KE. Early childhood screen time and parental attitudes toward child television viewing in a low-income Latino population attending the special supplemental nutrition program for women, infants, and children. Child. 2015;11:590-9. PM:26390321.

59. Nelson JA, Carpenter K, Chiasson MA. Diet, activity, and overweight among preschool-age children enrolled in the special supplemental nutrition program for women, infants, and children (WIC). Prev Chronic Dis. 2006;3: A49. PM:16539790
60. LaRowe TL, Adams AK, Jobe JB, Cronin KA, Vannatter SM, Prince RJ. Dietary intakes and physical activity among preschool-aged children living in rural American Indian communities before a family-based healthy lifestyle intervention. J Am Diet Assoc. 2010;110:1049-57. PM:20630162

61. Chen LP, Ziegenfuss JY, Jenkins SM, Beebe TJ, Ytterberg KL. Pediatric obesity and self-reported health behavior information. Clin Pediatr (Phila). 2011;50: 872-5. PM:21357199.

62. Minh Do LM, Tran TK, Eriksson B, Petzold M, Nguyen CTK, Ascher H. Preschool overweight and obesity in urban and rural Vietnam: differences in prevalence and associated factors. Glob Health Action. 2015;8:28615. PM: 26452338.

63. Hajian-Tilaki K, Heidari B. Childhood obesity, overweight, socio-demographic and life style determinants among preschool children in Babol, northern Iran. Iran J Public Health. 2013:42:1283-91. PM:26171341.

64. Koubaa AA, Younes K, Gabsi Z, Bouslah A, Maalel I, Maatouk EMW, et al. [risk factors of children overweight and obesity]. [French]. Tunis Med. 2012;90: 387-93. PM:22585646.

65. Sasaki A, Yorifuji T, Iwase T, Komatsu H, Takao S, Doi H. Is there any association between TV viewing and obesity in preschool children in Japan? Acta Med Okayama. 2010:64:137-42. PM:20424669.

66. Jouret B, Ahluwalia N, Cristini C, Dupuy M, Negre-Pages L, Grandjean H, et al. Factors associated with overweight in preschool-age children in southwestern France. Am J Clin Nutr. 2007;85:1643-9. PM:17556704.

67. Jiang J, Rosenqvist U, Wang H, Greiner T, Ma Y, Toschke AM. Risk factors for overweight in 2- to 6-year-old children in Beijing, China. Int J Pediatr Obes. 2006;1:103-8. PM:17907322.

68. Levin S, Martin MW, Riner WF. TV viewing habits and body mass index among South Carolina head start children. Ethn Dis. 2004;14:336-9. PM: 15328934.

69. Harrison K, Liechty JM. US preschoolers' media exposure and dietary habits: the primacy of television and the limits of parental mediation. J Children and Media. 2012;6:18-36.

70. Vandebosch $\mathrm{H}$, Cleemput KV. Television viewing and obesity among pre-school children: the role of parents. Communications. 2007;32: 417-46.

71. Mendoza JA, Zimmerman FJ, Christakis DA. Television viewing, computer use, obesity, and adiposity in US preschool children. Int J Behav Nutr Phys Act. 2007:4:44. PM:17894878

72. Fulton JE, Wang X, Yore MM, Carlson SA, Galuska DA, Caspersen CJ. Television viewing, computer use, and BMI among U.S. children and adolescents. J Phys Act Health. 2009;6 Suppl 1:S28-35. PM:19998847.

73. Twarog JP, Politis MD, Woods EL, Boles MK, Daniel LM. Daily television viewing time and associated risk of obesity among U.S. preschool aged children: an analysis of NHANES 2009-2012. Obes Res Clin Pract. 2015;9: 636-8.

74. Tremblay L, Rinaldi CM. The prediction of preschool children's weight from family environment factors: gender-linked differences. Eat Behav. 2010;11: 266-75. PM:20850062.

75. Jago R, Baranowski T, Baranowski JC, Thompson D, Greaves KA. BMI from 36 y of age is predicted by TV viewing and physical activity, not diet. Int J Obes. 2005;29:557-64. PM:15889113.

76. Taverno RS, Dowda M, Saunders R, Pate R. Double dose: the cumulative effect of TV viewing at home and in preschool on children's activity patterns and weight status. [erratum appears in Pediatr Exerc Sci. 2014 Feb;26(1):120]. Pediatr Exerc Sci. 2013;25: 262-72. PM:23502043.

77. Espana-Romero V, Mitchell JA, Dowda M, O'Neill JR, Pate RR. Objectively measured sedentary time, physical activity and markers of body fat in preschool children. Pediatr Exerc Sci. 2013;25:154-63. PM:23406703.

78. Collings PJ, Brage S, Ridgway CL, Harvey NC, Godfrey KM, Inskip HM, et al. Physical activity intensity, sedentary time, and body composition in preschoolers. Am J Clin Nutr. 2013;97:1020-8. PM:23553158.

79. Cardon G, De Bourdeaudhuij I, lotova V, Latomme J, Socha P, Koletzko B, et al. Health related behaviours in normal weight and overweight preschoolers of a large pan-European sample: the ToyBox-study. PLoS One. 2016;11(3):e0150580. 10.1371/journal.pone.0150580. PM:26950063.

80. Bonvin A, Barral J, Kakebeeke TH, Kriemler S, Longchamp A, Marques-Vidal P, et al. Weight status and gender-related differences in motor skills and in child care-based physical activity in young children. BMC Pediatr. 2012;12:23. PM:22405468. 
81. Reilly JJ, Armstrong J, Dorosty AR, Emmett PM, Ness A, Rogers I, et al. Early life risk factors for obesity in childhood: cohort study. BMJ. 2005;330:1357. PM:15908441.

82. Leary SD, Lawlor DA, Davey SG, Brion MJ, Ness AR. Behavioural early-life exposures and body composition at age 15 years. Nutr Diabetes. 2015;5: e150. PM:25664839.

83. Flores $\mathrm{G}$, Lin $\mathrm{H}$. Factors predicting overweight in US kindergartners. Am J Clin Nutr. 2013;97:1178-87. PM:23553169.

84. Gooze RA, Anderson SE, Whitaker RC. Prolonged bottle use and obesity at 5 . 5 years of age in US children. J Pediatr. 2011;159:431-6. PM:21543085.

85. Wheaton N, Millar L, Allender S, Nichols M. The stability of weight status through the early to middle childhood years in Australia: a longitudinal study. BMJ Open. 2015;5:e006963. PM:25922101.

86. Griffiths LJ, Hawkins SS, Cole TJ, Dezateux C. Millennium cohort study child health group. Risk factors for rapid weight gain in preschool children: findings from a UK-wide prospective study. Int J Obes. 2010; 34:624-32.

87. De Coen V, De Bourdeaudhuij I, Verbestel V, Maes L, Vereecken C. Risk factors for childhood overweight: a 30-month longitudinal study of 3 to 6-year-old children. Public Health Nutr. 2014;17:1993-2000. PM: 24172063.

88. Schmidt ME, Rich M, Rifas-Shiman SL, Oken E, Taveras EM. Television viewing in infancy and child cognition at 3 years of age in a US cohort. Pediatrics. 2009;123:e370-5. PM:19254972.

89. Fitzpatrick C, Pagani LS, Barnett TA. Early childhood television viewing predicts explosive leg strength and waist circumference by middle childhood. Int J Behav Nutr Phys Act. 2012;9:87. PM:22793018.

90. Pagani LS, Fitzpatrick C, Barnett TA, Dubow E. Prospective associations between early childhood television exposure and academic, psychosocial, and physical well-being by middle childhood. Arch Pediatr Adolesc Med. 2010;164:425-31. PM:20439793.

91. Hesketh KD, Crawford DA, Abbott G, Campbell KJ, Salmon J. Prevalence and stability of active play, restricted movement and television viewing in infants. Early Child Dev Care. 2015;185:883-94.

92. Pagani LS, Fitzpatrick C, Barnett TA. Early childhood television viewing and kindergarten entry readiness. Pediatr Res. 2013;74:350-5. PM: 23788060

93. De Kegel A, Peersman W, Onderbeke K, Baetens T, Dhooge I, Van Waelvelde $\mathrm{H}$. New reference values must be established for the Alberta infant motor scales for accurate identification of infants at risk for motor developmental delay in Flanders. Child Care Health Dev. 2013;39: 260-7. PM:22676145.

94. Lin LY, Cherng RJ, Chen YJ, Yang HM. Effects of television exposure on developmental skills among young children. Infant Behav Dev. 2015;38: 20-6. PM:25544743.

95. Watt E, Fitzpatrick C, Derevensky JL, Pagani LS. Too much television? Prospective associations between early childhood televiewing and later selfreports of victimization by sixth grade classmates. J Dev Behav Pediatr. 2015;36:426-33. PM:26075581.

96. Hinkley T, Verbestel V, Ahrens W, Lissner L, Molnar D, Moreno LA, et al. Early childhood electronic media use as a predictor of poorer wellbeing: a prospective cohort study. JAMA Pediatr. 2014;168:485-92. PM: 24639016.

97. Verlinden $M$, Tiemeier $H$, Veenstra $R$, Mieloo $C L$, Jansen $W$, Jaddoe WWV, et al. Television viewing through ages 2-5 years and bullying involvement in early elementary school. BMC Public Health. 2014;14: 157. PM:24520886

98. Intusoma U, Mo-Suwan L, Ruangdaraganon N, Panyayong B, Chongsuvivatwong V. Effect of television viewing on social-emotional competence of young Thai children. Infant Behav Dev. 2013;36:679-85. PM: 23948636.

99. Verlinden M, Tiemeier H, Hudziak JJ, Jaddoe WW, Raat H, Guxens M, et al. Television viewing and externalizing problems in preschool children: the generation R study. Arch Pediatr Adolesc Med. 2012;166:919-25. PM: 22869354

100. Cheng S, Maeda T, Yoichi S, Yamagata Z, Tomiwa K, Japan Children's study group. Early television exposure and children's behavioral and social outcomes at age 30 months. J Epidemiol. 2010;20 Suppl 2:S482-9. PM:20179364.

101. Manganello JA, Taylor CA. Television exposure as a risk factor for aggressive behavior among 3-year-old children. Arch Pediatr Adolesc Med. 2009;163: 1037-45. PM:19884595.
102. Mistry KB, Minkovitz CS, Strobino DM, DLG B. Children's television exposure and behavioral and social outcomes at 5.5 years: does timing of exposure matter? Pediatrics. 2007;120:762-9. PM:17908763.

103. Zimmerman FJ, Glew GM, Christakis DA, Katon W. Early cognitive stimulation, emotional support, and television watching as predictors of subsequent bullying among grade-school children. Arch Pediatr Adolesc Med. 2005:159:384-8. PM:15809395

104. Irwin JD, Johnson AM, Vanderloo LM, Burke SM, Tucker P. Temperament and objectively measured physical activity and sedentary time among Canadian preschoolers. Prev Med Rep. 2015;2:598-601. PM:26844125.

105. Teramoto S, Soeda A, Hayashi Y, Saito K, Urashima M. Problematic behaviours of 3-year-old children in Japan: relationship with socioeconomic and family backgrounds. Early Hum Dev. 2005;81: $563-9$.

106. Miller LE, Grabell A, Thomas A, Bermann E, Graham-Bermann SA. The associations between community violence, television violence, intimate partner violence, parent-child aggression, and aggression in sibling relationships of a sample of preschoolers. Psychology of Violence. 2012;2: 165-78.

107. Linebarger DL. Contextualizing video game play: the moderating effects of cumulative risk and parenting styles on the relations among video game exposure and problem behaviors. Psychol Pop Media Cult. 2015;4: 375-96.

108. Byeon H, Hong S. Relationship between television viewing and language delay in toddlers: evidence from a Korea national cross-sectional survey. PLoS One. 2015;10:e0120663. PM:25785449.

109. Rajchanovska D, Ivanovska BZ. The impact of demographic and socioeconomic conditions on the prevalence of speech disorders in preschool children in Bitola. Srp Arh Celok Lek. 2015;143:169-73. PM:26012126.

110. Linebarger DL, Barr R, Lapierre MA, Piotrowski JT. Associations between parenting, media use, cumulative risk, and children's executive functioning. J Dev Behav Pediatr. 2014;35:367-77. PM:25007059.

111. Duch H, Fisher EM, Ensari I, Font M, Harrington A, Taromino C. Association of screen time use and language development in Hispanic toddlers: a crosssectional and longitudinal study. Clin Pediatr (Phila). 2013;52:857-65. PM: 23820003

112. Tomopoulos S, Dreyer BP, Berkule S, Fierman AH, Brockmeyer C, Mendelsohn AL. Infant media exposure and toddler development. Arch Pediatr Adolesc Med. 2010;164:1105-11. PM:21135338.

113. Foster EM, Watkins S. The value of reanalysis: TV viewing and attention problems. Child Dev. 2010;81:368-75. PM:20331673.

114. Zimmerman FJ, Gilkerson J, Richards JA, Christakis DA, Xu D, Gray S, et al. Teaching by listening: the importance of adult-child conversations to language development. Pediatrics. 2009;124:342-9. PM:19564318.

115. Ruangdaraganon N, Chuthapisith J, Mo-Suwan L, Kriweradechachai S, Udomsubpayakul U, Choprapawon C. Television viewing in Thai infants and oddlers: impacts to language development and parental perceptions. BMC Pediatr. 2009;9:34. PM:19460170.

116. Chonchaiya W, Pruksananonda C. Television viewing associates with delayed language development. Acta Paediatr. 2008;97:977-82. PM:18460044.

117. Zimmerman FJ, Christakis DA, Meltzoff AN. Associations between media viewing and language development in children under age 2 years. J Pediatr. 2007:151:364-8. PM:17889070.

118. Miller CJ, Marks DJ, Miller SR, Berwid OG, Kera EC, Santra A, et al. Brief report: television viewing and risk for attention problems in preschool children. J Pediatr Psychol. 2007;32:448-52. PM:17012738.

119. Zimmerman FJ, Christakis DA. Children's television viewing and cognitive outcomes: a longitudinal analysis of national data. Arch Pediatr Adolesc Med. 2005;159:619-25. PM:15996993.

120. Christakis DA, Zimmerman FJ, DiGiuseppe DL, McCarty CA. Early television exposure and subsequent attentional problems in children. Pediatrics. 2004; 113:708-13. PM:15060216.

121. McKean C, Mensah FK, Eadie P, Bavin EL, Bretherton L, Cini E, et al. Levers for language growth: characteristics and predictors of language trajectories between 4 and 7 years. PLoS One. 2015;10:e0134251.

122. Blankson A. Do hours spent viewing television at ages 3 and 4 predict vocabulary and executive functioning at age 5? Merrill-Palmer Q. 2015; 61:264-89.

123. Nathanson Al, Fries PT. Television exposure, sleep time, and neuropsychological function among preschoolers. Media Psychology. 2014; $17: 237-61$. 
124. Ferguson CJ, Donnellan MI. The association between children's baby video viewing and poor language development robust? A reanalysis of Zimmerman, Christakis, and Meltzoff (2007). Dev Psychol. 2014;50: 129-37.

125. Herrmann D, Buck C, Sioen I, Kouride Y, Marild S, Molnar D, et al. Impact of physical activity, sedentary behaviour and muscle strength on bone stiffness in 2-10-year-old children - cross-sectional results from the IDEFICS study. Int J Behav Nutr Phys Act. 2015;12:112. PM: 26377674.

126. Crispim PA, Peixoto MR, Jardim PC. Risk factors associated with high blood pressure in two-to five-year-old children. Arq Bras Cardiol. 2014;102:39-46. PM:24263779.

127. Wilmot EG, Edwardson CL, Achana FA, Davies MJ, Gorely T, Gray LJ, et al, Sedentary time in adults and the association with diabetes, cardiovascular disease and death: systematic review and meta-analysis. Diabetologia. 2012; 55:2895-905. PM:22890825.

128. Cliff DP, Okely AD. Comparison of two sets of accelerometer cut-off points for calculating moderate-to-vigorous physical activity in young children. J Phys Act Health. 2007:4:509-13. PM:18209240.

129. Colley RC, Harvey A, Grattan KP, Adamo KB. Impact of accelerometer epoch length on physical activity and sedentary behaviour outcomes for preschool-aged children. Health Rep. 2014;25:3-9. PM:24430918.

130. Kabali HK, Irigoyen MM, Nunez-Davis R, Budacki JG, Mohanty SH, Leister KP, et al. Exposure and use of mobile media devices by young children Pediatrics. 2015;136:1044-50. PM:26527548.

131. Mazarello Paes V, Ong KK, Lakshman R. Factors influencing obesogenic dietary intake in young children (0-6 years): systematic review of qualitative evidence. BMJ Open. 2015;5:e007396. PM:26377503.

132. Christakis DA, Gilkerson J, Richards JA, Zimmerman FJ, Garrison MM, Xu D, et al. Audible television and decreased adult words, infant vocalizations, and conversational turns: a population-based study. Arch Pediatr Adolesc Med. 2009;163:554-8. PM:19487612.

133. Ridgers ND, Salmon J, Ridley K, O'Connell E, Arundell L, Timperio A. Agreement between activPAL and ActiGraph for assessing children's sedentary time. Int J Behav Nutr Phys Act. 2012;9:15. PM:22340137.

\section{Submit your next manuscript to BioMed Central and we will help you at every step:}

- We accept pre-submission inquiries

- Our selector tool helps you to find the most relevant journal

- We provide round the clock customer support

- Convenient online submission

- Thorough peer review

- Inclusion in PubMed and all major indexing services

- Maximum visibility for your research

Submit your manuscript at www.biomedcentral.com/submit

) Biomed Central 